Chapman University

Chapman University Digital Commons

Pharmacy Faculty Articles and Research

School of Pharmacy

2015

\title{
Peptide Bacteriocins - Structure Activity Relationships
}

Hashem Etayash

University of Alberta

Sarfuddin Azmi

University of Alberta

Ramana Dangeti

University of Alberta

Kamaljit Kaur

Chapman University, kkaur@chapman.edu

Follow this and additional works at: http://digitalcommons.chapman.edu/pharmacy_articles

\section{Recommended Citation}

Etayash H., Azmi S., Dangeti, R., Kaur K., 2015. Peptide Bacteriocins - Structure Activity Relationships. Current Topics in Medicinal Chemistry 15. DOI: $10.2174 / 1568026615666150812121103$

This Article is brought to you for free and open access by the School of Pharmacy at Chapman University Digital Commons. It has been accepted for inclusion in Pharmacy Faculty Articles and Research by an authorized administrator of Chapman University Digital Commons. For more information, please contact laughtin@chapman.edu. 


\section{Peptide Bacteriocins - Structure Activity Relationships}

\section{Comments}

This is a pre-copy-editing, author-produced PDF of an article accepted for publication in Current Topics in Medicinal Chemistry, volume 15, in 2015 following peer review. The definitive publisher-authenticated version will be available online at DOI: 10.2174/1568026615666150812121103.

\section{Copyright}

Bentham Science 


\section{Peptide Bacteriocins - Structure Activity Relationships}

Hashem Etayash ${ }^{1,2}$, Sarfuddin Azmi ${ }^{1}$, Ramana Dangeti ${ }^{1}$, and Kamaljit Kaur ${ }^{1,3,{ }^{*}}$

${ }^{1}$ Faculty of Pharmacy and Pharmaceutical Sciences, University of Alberta, Edmonton, Alberta, T6G 2E1, Canada

${ }^{2}$ Department of Chemical and Materials Engineering, University of Alberta, Edmonton, Alberta, T6G 2V4, Canada

${ }^{3}$ Chapman University School of Pharmacy (CUSP), Harry and Diane Rinker Health Science Campus, Chapman University, Irvine, CA, 92618-1908, USA

Corresponding author:

*Email: kkaur@chapman.edu 


\begin{abstract}
With the growing concerns in the scientific and health communities over increasing levels of antibiotic resistance, antimicrobial peptide bacteriocins have emerged as promising alternative to conventional small molecule antibiotics. A substantial attention has recently focused on the utilization of bacteriocins in food preservation and health safety. Despite the fact that a large number of bacteriocins have been reported, only a few have been fully characterized and structurally elucidated. Since knowledge of the molecular structure is a key for understanding the mechanism of action and therapeutic effects of peptide, we centered our focus in this review on the structure-activity relationships of bacteriocins with a particular focus in seven bacteriocins, namely, nisin, microcin $\mathrm{J} 25$, microcin $\mathrm{B} 17$, microcin $\mathrm{C}$, leucocin $\mathrm{A}$, sakacin $\mathrm{P}$, and pediocin PA-1. Significant structural changes responsible for the altered activity of the recent bacteriocin analogues are discussed here.
\end{abstract}

KEYWORDS: Bacteriocins, Structure-Activity Relationship, Bacteriocin Analogues 
Table of Contents

1. INTRODUCTION

2. CLASS I BACTERIOCINS

2.1 Nisin

2.2 Microcin J25 (MccJ25)

2.3 Microcin B17 (MccB17)

2.4 Microcin C (MccC)

3. CLASS II BACTERIOCINS

3.1 Class IIa Bacteriocins

Pediocin PA-1

Leucocin A (LeuA)

Sakacin P

3.2 Class IIb Bacteriocins

3.3 Class II Microcins

4. CHALLENGES AND FUTURE

5. CONCLUSION 


\section{INTRODUCTION}

Eukaryotic and prokaryotic cells produce ribosomally synthesized antimicrobial peptides that have significant effect against several harmful microorganisms [1]. When produced by bacteria, these antimicrobial peptides are referred to as bacteriocins [2]. Bacteriocins were first discovered by A. Gratia in 1925 when he was involved in the process of searching for approaches to kill bacteria. He called his first bacteriocin that killed E. coli a colicin [3]. Generally bacteriocins are small, very potent antimicrobial peptides (proteinaceous toxins), made by bacteria to inhibit the growth of alike or closely related bacterial strains. Typically bacteriocins have narrow spectrum of activity; however, few of them are shown with broad spectrum and wide range of activities. Bacteriocins have also been considered as analogous to yeast and paramecium killing agents, which are structurally and functionally different [4-7].

Throughout the years of discovery, several approaches have been taken to classify bacteriocins into a number of categories that include nature of the producing strains, the methods by which these molecules are produced, common resistance mechanisms and the peptides mechanism of actions [1]. The most widely studied bacteriocins are classified into class I and class II bacteriocins. Class I consists of small, heat stable $(<10 \mathrm{kDa})$ post-translationally modified peptides, while class II are small, heat stable $(<10 \mathrm{kDa})$ less extensive post-translationally modified peptides, and each class is further divided into subclasses based on structure and modifications (Table 1). Bacteriocins are very potent antimicrobial peptides typically active in the nanomolar range, and some of them are 
produced by food grade microorganisms rendering them extremely safe and potential candidates for applications in food safety and clinical settings $[2,8]$.

Table 1. Classification of bacteriocins

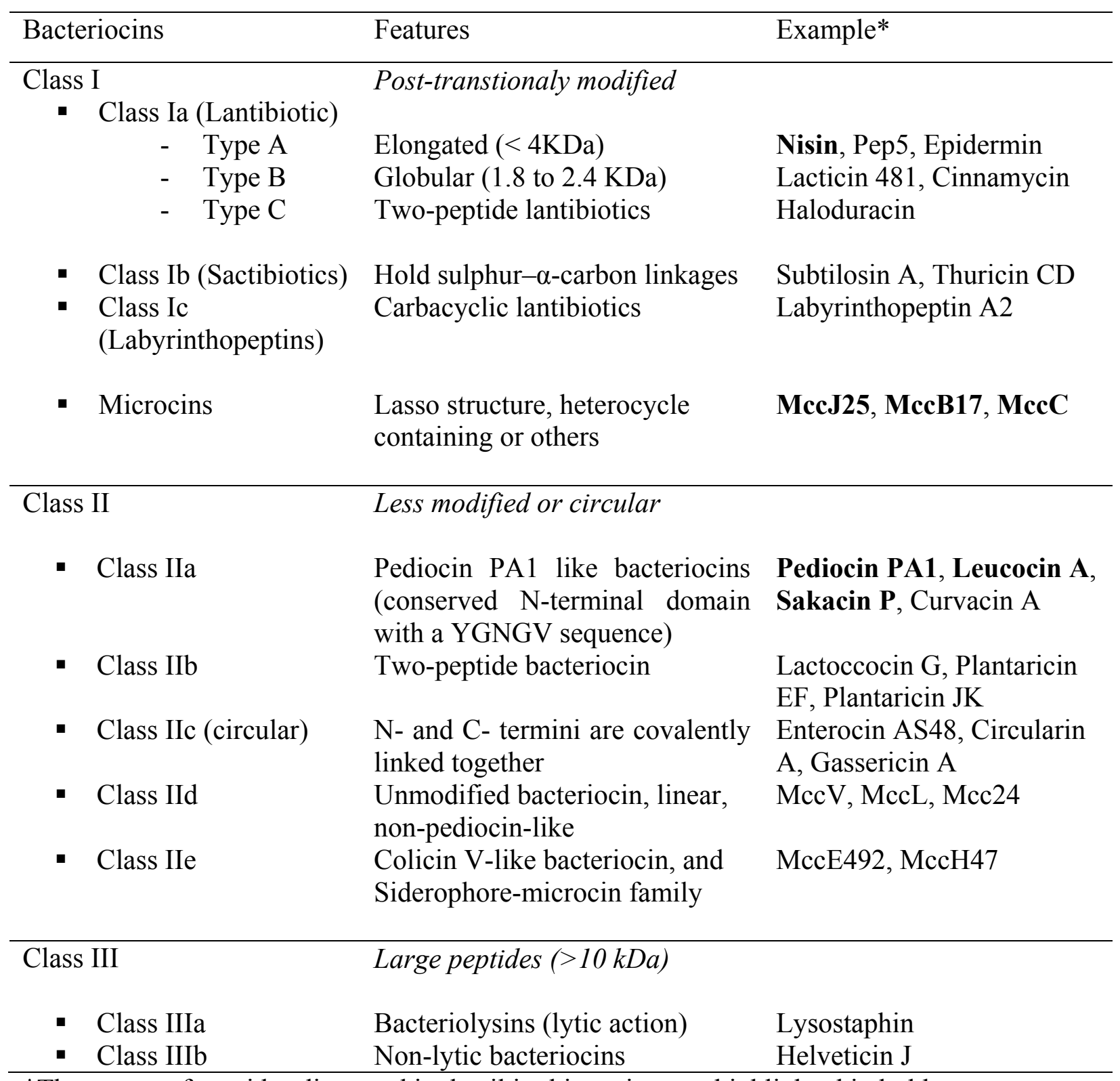

*The names of peptides discussed in detail in this review are highlighted in bold. 
Bacteriocins are quite unique with respect to their mechanism of action $[9,10]$. In general, bacteriocins act via interactions with a specific receptor on the target cell. This interaction leads to permeabilization of the cell membrane of the target cell, triggering outflow of intracellular components and disintegration of the proton-motive force. For instance, Nisin and other lantibiotics bind to lipid II as a target molecule to kill the bacteria $[10,11]$. Recently it has been revealed that lipid II is the target of several antibiotics and antifungal agents. Certain peptides of class II bacteriocins such as pediocin-like bacteriocins and lactococcins bind to specific membrane active receptors in order to express their activity. A membrane protein component of the mannose phosphotransferase (man-PTS) system has been revealed to be the actual target site of these bacteriocins [12-14]. Not only bacteriocins from Gram-positive bacteria are using the man-PTS as the target for killing cells, it has been shown that certain microcins from Gram-negative bacteria required this membrane receptor to show activity $[15,16]$.

Despite the long-history of bacteriocins, only nisin and few other bacteriocins have reached market and have been used in industry as food preservatives with very little resistance development $[8,17]$. There are clear limitations in the industrial and clinical applications of bacteriocins, which is a result of a number of drawbacks and challenges that have yet to be resolved. Many of these AMPs are prone to degradation by digestive enzymes and metabolic proteins present in the food products, GI tract and blood circulation [18-22]. Stability at harsh environments is also an issue for bacteriocins; as an example, lantibiotics undergo oxidation in basic $\mathrm{pH}$, resulting in loss of its main 
bacteriocidal activity [20,23]. Existence of such disadvantages and the scientists desire to exploit the prospects of bacteriocins as safe and potent antibacterial agents have driven much effort towards exploring the structural-activity relationships (SARs) of bacteriocins. The better understanding of the SARs can render more stable highly active analogues with higher possibility of developing novel antibiotics from bacteriocins.

In this review we center our focus on the structural-activity relationships of bacteriocins, reviewing the recent novel analogues of the most-well characterized bacteriocins, discussing the challenges that hinder bacteriocins from being on the marketplace and finally stressing on the future potential of the analogues.

\section{CLASS I BACTERIOCINS}

Class I bacteriocins are ribosomally synthesized, small membrane-active antimicrobial peptides with molecular sizes of $<5 \mathrm{kDa}$. Generally, they contain unusual amino acids such as lanthionine or $b$-methyl lanthionine in their sequences and are therefore called post-translationally modified bacteriocins [24]. Nisin is the most well studied and characterized AMP of class I bacteriocins. The class has been subdivided into three categories including, class Ia (the lantibiotics), class Ib (the sactibiotics) and class Ic (the labyrinthopeptins) [1].

In general, lantibiotics or class Ia peptides contain more than one post-translationally modified amino acid residue. These could be lanthionine (Lan), methyl lanthionine (MeLan), dehydroalanine (Dha), dehydrobutyrine (Dhb), 2-oxobutyryl, 
aminovinylmethyl-D-cysteine, labionin (Lab), or other similar modified amino acid residues. Due to structural complexity class Ia bacteriocins are further subdivided into three classes, namely, type A (linear), type B (globular), and type C (two-peptide) [25]. The linear or the type A lantibiotics includes nisin, pep5, epidermin and subtilin, which were assembled on the basis of sequence length ( $\sim 34$ amino acid residues) and amphiphilic structure. On the other hand, globular lantibiotics or type B that include lacticin 481, mercsacidin, cinnamycin, and mutacin II, were assembled together according to their compact structures and length of amino acid residues ( $\sim 19$ residues) [25]. Type $\mathrm{C}$ are two-peptide bacteriocins where two separate sequences together display synergistic activity. Lantibiotics are typically produced by Gram-positive bacteria, mainly lactic acid bacteria (LAB), to target other bacterial species such as Listeria monocytogenes, Clostridium botulinum, Enterococcus and the resistant strains of Staphylococcus aureus.

Another type of class I bacteriocins are microcins that are produced ribosomally by Gram-negative Enterobacteria as host defence molecules, to strive and thrive in the midst of bacterial community [26-29]. Microcins are classified into class I and class II on the basis of molecular masses, disulfide bridges, and the extent of posttranslational modification. Class I microcins are small sized $(<5 \mathrm{kDa})$ and highly post-translationally modified peptides, like Microcin J25 (MccJ25), MccB17, and MccC (C7-C51). Class II are comparatively higher molecular mass antimicrobial peptides $(>5$ to $<10 \mathrm{kDa})$ with subtle or no post-translational modifications. As compared to other bacterial origin antimicrobial peptides, like colicins (high molecular size derived from Gram-negative 
bacteria) $[30,31]$ and bacteriocins derived from Gram-positive bacteria [1, 32], microcins have been studied to a lesser extent. Till date, fourteen microcins have been discovered and out of this, eight have been characterized structurally and to some extent functionally [1]. Most of the well-characterized microcins belong to class I and have been studied using SARs dealing with substitutions, deletion, truncation or other modifications of the original sequence. As we see in literature, most of the works have taken place on some of the microcins like MccJ25, MccB17, Mcc C7/C51, MccE492 and Mcc M, V and L; therefore in this section of review our discussion will revolve around these peptides.

Extensive reviews have been reported for lantibiotics [9, 33-39], therefore here we will limit our discussion to four class I bacteriocins, namely, nisin, microcins MccJ25, MccB17, and MccC.

\subsection{Nisin}

Nisin, the most popular class I bacteriocin first marketed in England in 1953, is now approved for use as a food preservative in 48 countries.[24] The full structure of nisin, however, was elucidated in early 1970s [40]. It has several natural variants, including nisin A (res 27-His) and nisin Z (res 27-Asn) as most common forms (Table 2). Nisin typically contains one lanthionine (ring A) and four methyl lanthionine rings (rings B-E), along with three dehydrated amino acid residues as shown in Fig (1). This highly potent peptide is not only active against the important food-spoilage bacteria such as Listeria monocytogenes and Clostridium botulinum, but also has a potential for use as a human therapeutic, especially for treatments of drug-resistant bacterial infections [41-44]. 
Table 2. Amino acid sequences of common variants of Nisin in nature.

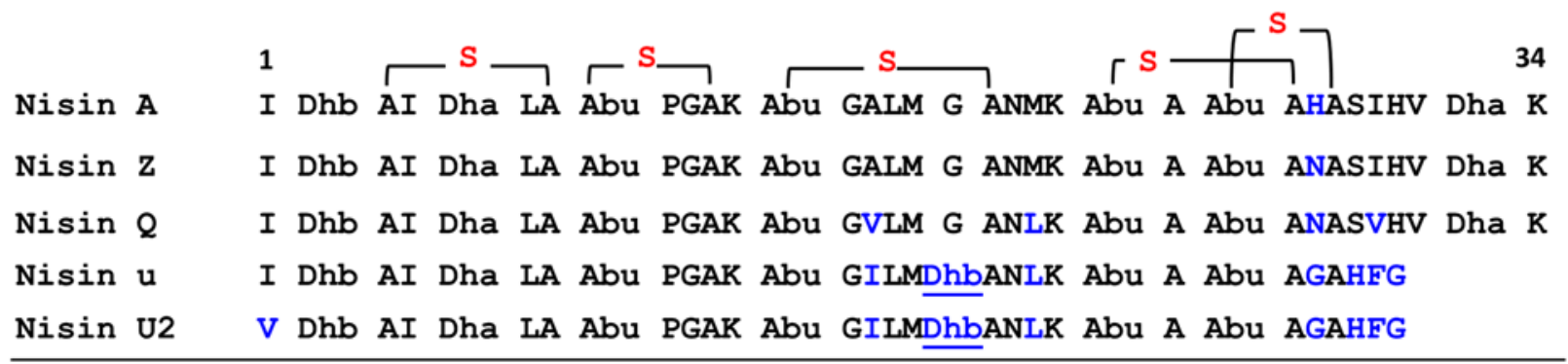

Abu: aminobutyric acid; Dha: Dehydroalanine; Dhb: Dehydrobutyrine; ring $\mathrm{S}$ is only shown for the Nisin A here, however, it is similarly present in all the variants.

In order to explore the SARs of nisin, several analogues have been made since its discovery using either site directed mutagenesis or chemical synthesis. A number of mutations at rings $\mathrm{A}$ and $\mathrm{B}$ have been implemented (Fig 1a) [45]. The findings showed that a large number of nisin mutants indeed retained the biological activity of the peptide. In fact, some double and triple mutants presented higher potency than the wild type nisin against the indicator microorganisms. The study also suggested that introduction of a positive charge to the ring A has a positive impact on nisin's biological activity. Among the mutations on ring A, only three mutants were matching the native peptide, as they do not possess aromatic residues in the ring A. This is an indication of flexibility of the ring A with regard to the amino acid substitutions [45]. In contrast to ring A, ring B was found to be very sensitive to amino acid exchanges. Size of amino acids is a dispute as bulky residues give poor or no activity. The loss of ability to cyclize the ring B between positions 8 and 11 diminished peptide activity. Further explorations were performed by making truncated analogues of the peptide where residues $23-34$ were alternated. 


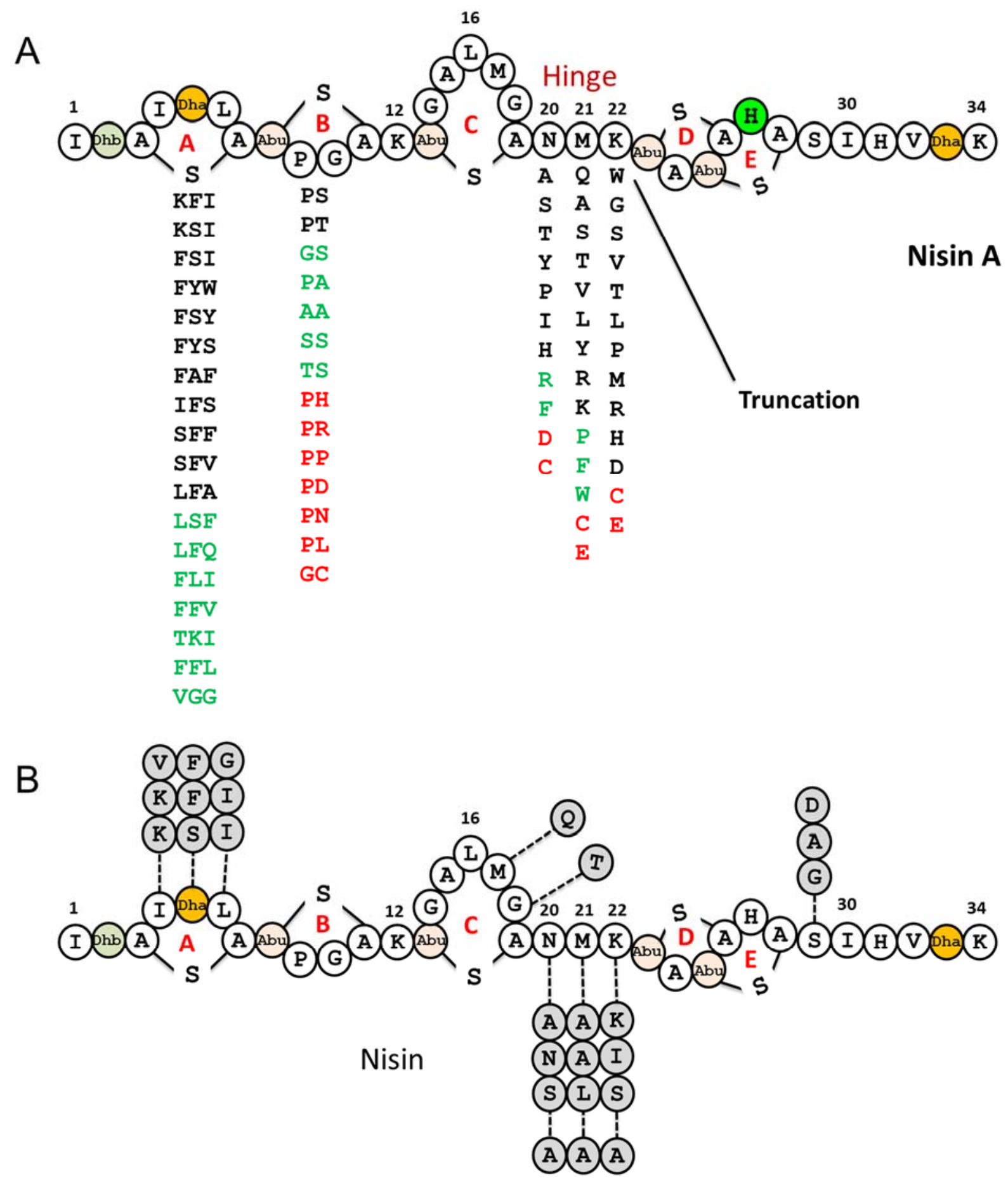

Fig. (1). Analogues of nisin A with mutations at positions $4 / 5 / 6$ or $9 / 10$ or the hinge region (positions 20/21/22). The five rings are labeled as A, B, C, D, and E. (A) Nisin A analogues with high activity are shown in black, weakly-active in green and inactive mutants are presented in red. (B) Coded circles (gray color) show the activity enhancing amino acid substituents. AAA derivative of Nisin A displayed higher activity than the native nisin. 
Substantial reduction in activity was observed in most cases; however, when the triple mutant KFI and the native nisin were truncated, there were only 10 -fold loss of activity compared to the wild type nisin. Additional studies of their mechanism of actions indicated that these peptides act solely by interference with lipid II and cell-wall biosynthesis.

In recent years, the hinge region of nisin has also received considerable attention, where several mutations have been tried [46]. Interestingly, three mutants, N20P, M21V and $\mathrm{K} 22 \mathrm{~T}$, showed activity greater than the native type nisin A. While the mutants $\mathrm{N} 20 \mathrm{P}$ and K22T displayed activity against S. aureus and Streptococcus agalactiae, respectively, the M21V mutant displayed activity against Listeria monocytogenes, suggesting a potential use as a food preservative.

Nisin recently went through several bioengineering processes in order to improve its function and physico-chemical properties. A notable example in a report by Des Field et al [47] showed novel nisin variants with enhanced activity against clinical and foodborne pathogens. In their study, they screened a randomized bank of nisin A producers and identified a variant with a serine to glycine change at position 29 (S29G), with enhanced efficacy against $S$. aureus SA113 Fig (1a). Furthermore, using the site-directed mutagenesis, they generated three more derivatives of nisin A (S29A, S29D and S29E) with enhanced activity against a range of Gram-positive drug resistant bacteria. In addition, a number of the nisin S29 derivatives exhibited superior antimicrobial activity 
to nisin A when evaluated against a range of Gram-negative food-borne pathogens, including E. coli, Salmonella enterica and Cronobacter sakazakii [47].

Further exploration by Cotter and co-workers showed that altering the three amino acids at the hinge region ((N20, M21 and K22), which separates the two domains of nisin and allows for conformational flexibility with other amino acid residues (AAK, NAI or SLS), display enhanced bioactivity against a variety of target strains [48] (Fig 1b). Furthermore, the structure of the mature nisin A peptide derivative AAA has been revealed to exhibit a higher inhibition to bacterial growth than the native nisin A. The study suggested that addition of small chiral amino acids such as alanine or serine to the hinge region resulted in an increase in bioactivity of the peptide and it can most likely be attributed to an increase in the 'hinge' flexibility. In contrast, the assembly of the achiral glycine in the 'hinge' region may confer a structurally weak hyper flexible 'hinge' lacking in any distinct conformity through mis-folding [48]. Recently the hinge region (NMK) was genetically engineered to vary from one to six amino acids in length, and then tested against various pathogenic strains such as Listeria monocytogenes, Enterococcus faecalis VE14089, Lactococcus lactis MG1363 etc. The results of an agar diffusion assay showed that some variants with one or two amino acids extra or less $(+2,+1,-1,-2)$ exhibited higher activity than the wild type nisin [49]. These studies supported positive impact of the hinge region variability of nisin toward its bioactivity and specificity. 
Taking advantage of bioengineering technology and the site-directed mutagenesis, Evelyn et al. have utilized the techniques and generated a bank of nisin A derivatives in which K12 was substituted with all other standard amino acid residues Fig (2) [50]. The study demonstrated that altering the K12 residue of nisin A can generate peptide analogues with better antibacterial activity. The finding showed enhanced activity towards food associated strains of bacteria and suggested that standard industrial nisin purification/fermentation methods could be utilized [50].

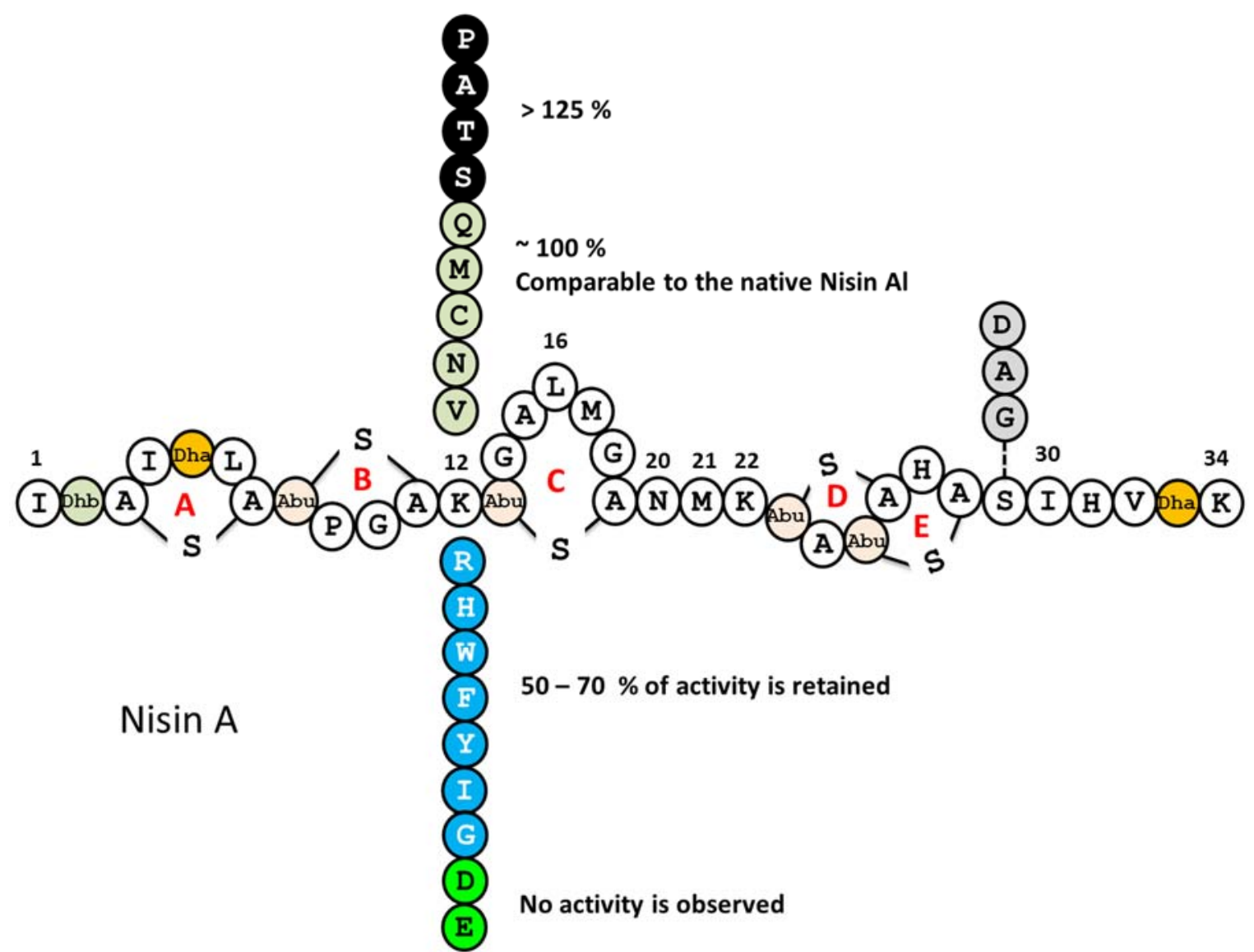

Fig. (2). Bioengineering technology showed enhanced bioactivity of the wild type lantibiotic nisin A. Mutation at lysine 12 showed enhanced, decreased or abolished activity of Nisin A as indicated above. 
Nisin is also used as a template for designing novel peptide-based antibiotics to improve its drug-like properties. In this regard, several research groups have focused on development of a nisin hybrid and a synthetic active bioconjugate for nisin. A study by Slootweg Jack et al. reported the development of a nisin hybrid with comparable activity to the native nisin [51]. The study involved digestion of the full-length nisin between $\mathrm{ABC}$ ring and $\mathrm{DE}$ ring regions using chymotrypsin treatment. The $\mathrm{ABC}$ ring was subsequently functionalized at the C-terminal with two different amino alkyne moieties. The nisin hybrids were prepared using the $\mathrm{Cu}(\mathrm{I})$-catalyzed azide alkyne cycloaddition 'click' chemistry by chemo-selective ligation of the ABC-alkyne with the N-terminal azido functionalized dicarba-DE ring mimic Fig (3a). The new products had similar activity to the wild-type nisin and showed strong binding to lipid II. Similarly, synthetic nisin derivatives made by $\mathrm{C}$-terminal modifications were able to retain both the antimicrobial activity and the membrane permeabilizing properties of the wild-type nisin, suggesting the importance of the $\mathrm{ABC}$ rings and the $\mathrm{C}$-terminal modification of nisin does not deteriorate the biological activity in sharp contrast to the N-terminal modification Fig (3). The reported studies compare well with previous studies with regard to the important role of the $\mathrm{AB}$ ring. Arnusch et al conjugated nisin to vancomycin and the conjugate exhibited 40-fold enhancement in biological activity [52]. Here the nisin fragment (1-12) that binds to the polyphosphate moiety of lipid II was prepared by enzymatic cleavage and was C-terminally conjugated to vancomycin using the click chemistry [52]. 

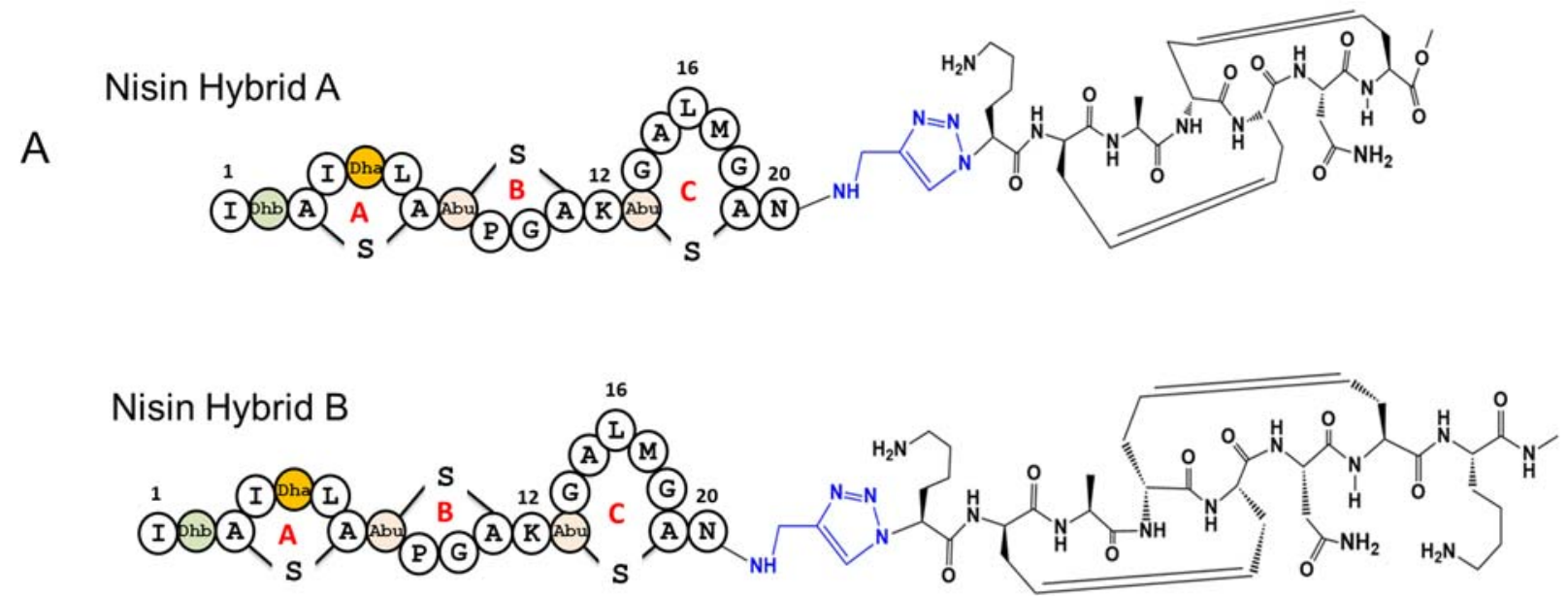

B Nisin-vancomycin Conjugate

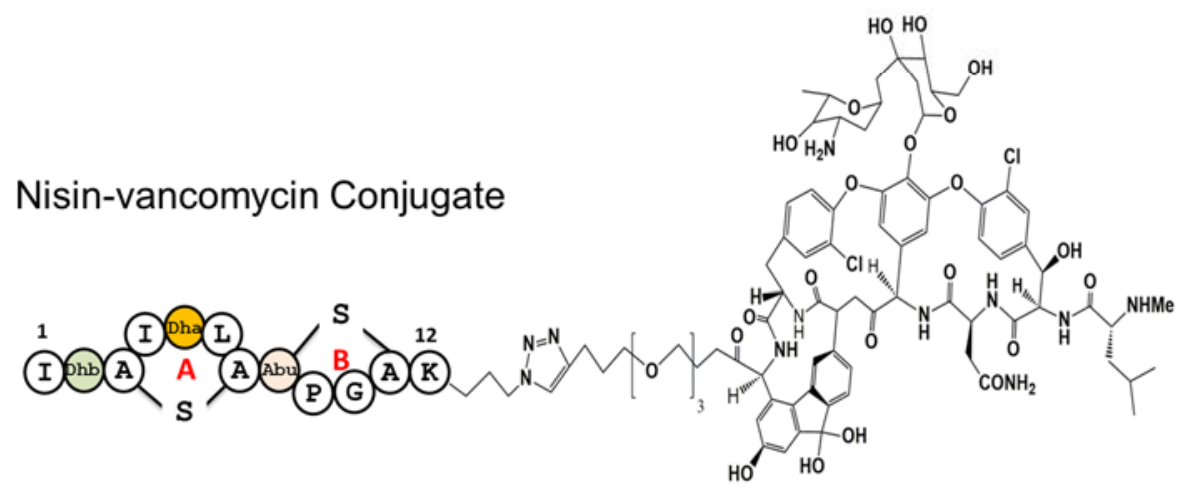

Fig. (3). Structures of Nisin-conjugates. (A) Nisin hybrids A and B that show comparable activity to the wild type nisin A. (B) Nisin fragment (1-12) conjugated to vancomycin that shows 40 -fold increase in activity.

In contrast to the $\mathrm{C}$-terminal modification, $\mathrm{N}$-terminal modification of nisin is generally problematic, as it may hinder the peptide binding to the target lipid II. Although the exact details are not clearly understood, it is been suggested that rings $\mathrm{A}$ and $\mathrm{B}$, which are towards the $\mathrm{N}$-terminal, bind to the cell wall and form a cage-like structure with the pyrophosphate moiety of lipid II. As a result of this complex, the D and E rings, which are at the C-terminal, are positioned in such a way that they can form pores in the cell membrane of the target. Thus, losing the initial binding part or the "N-terminus region" in 
the case of nisin will stop the activity at the first place. In agreement with the phenomena, PEGylation of nisin at the N-terminus completely diminished its activity [53]. While truncated mutants lacking the C-terminal rings display some antibacterial action as it has been discussed previously.

As yet, nisin is the only lantibiotic bacteriocin that has reached the market with a widespread use as food preservative [54]. Nisin's wide application as a safe alternative to chemical agents in food products with no bacterial resistance has stimulated expansions of the research in lantibiotics towards the development of new lantibiotics with better bioactivity and no resistance. Despite its use in food industry, nisin is still far away from the clinical applications and that is due to a number of obstacles that still remain to be resolved [55, 56]. The pharmacokinetic and in vivo properties of nisin need to be optimized for clinical use. However, by better knowledge of lantibiotics' SARs, it would be possible to modify these antimicrobial peptides to circumvent barriers that hinder their medical applications. In addition, SAR will allow the development of novel antibiotics with superior activities and no resistance.

\subsection{Microcin J25 (MccJ25)}

Among all discovered microcins, MccJ25 is the most well studied microcin up to date. In 1992 Salmon et al. for the first time isolated and characterized MccJ25 as 20 amino acid peptide with blocked N-terminal amino acid [57]. Later on, Blond et al. in 1999 reported a head-to-tail ring 21 amino acid macrocylic peptide [58]. In 2003, three research groups independently testified that $\mathrm{J} 25$ is noose-like ring peptide rather than head to tail [59-61]. 
The sequence of $\mathrm{J} 25$ is rich in hydrophobic amino acids and back bone folded in very unusual lasso structure, the carboxyl functional group of side chain of Glu8 and Nterminal Gly covalently linked and formed small lactam ring like structure and c-terminal squeeze through this ring to form lasso (Fig 4a). This lasso structure stabilized by aromatic side chain of Phe19 and Tyr20 located on either side of the ring prevents slipping out c-terminal tail. This unusual noose structure of $\mathrm{J} 25$ provides great stability against adverse condition like high temperature, proteases and chaotropic agents. However, in very harsh acidic environment or in the presence of endopeptidases like thermolysin the loop produces two-chain peptide without removing the c-terminal tail threaded through macrolactam ring [62,63]. This plasmid encoded posttranslationally modified antimicrobial peptide exhibit potent activity (MIC $\sim 2-50 \mathrm{nM}$ ) against Salmonella species and non-producing E. coli strains. The potent narrow spectrum antibacterial activity of MccJ25 is gained through stalling the secondary channel of RNA polymerase, inhibiting membrane respiratory chain and dissipating diffusion potential across the cytoplasmic membrane after getting access through siderophore receptor fhuA of outer membrane and inner membrane complex [64].

In order to understand the importance of sequence over conformation, several groups designed different analogues considering different parameters. In 2004, Bollomio et al. noticed that thermolysin cleaved $\mathrm{J} 25$ does not inhibit $E$ coli growth but shows in vitro inhibition of the RNA polymerase activity [65]. Similarly, Somenova et al. reported that chemically degraded b-hairpin region (13 - 17 and 15 - 17) analogue of J25 still exhibits comparative RNA polymerase inhibition [66]. Furthermore, in 2008 Pavlova et al. 


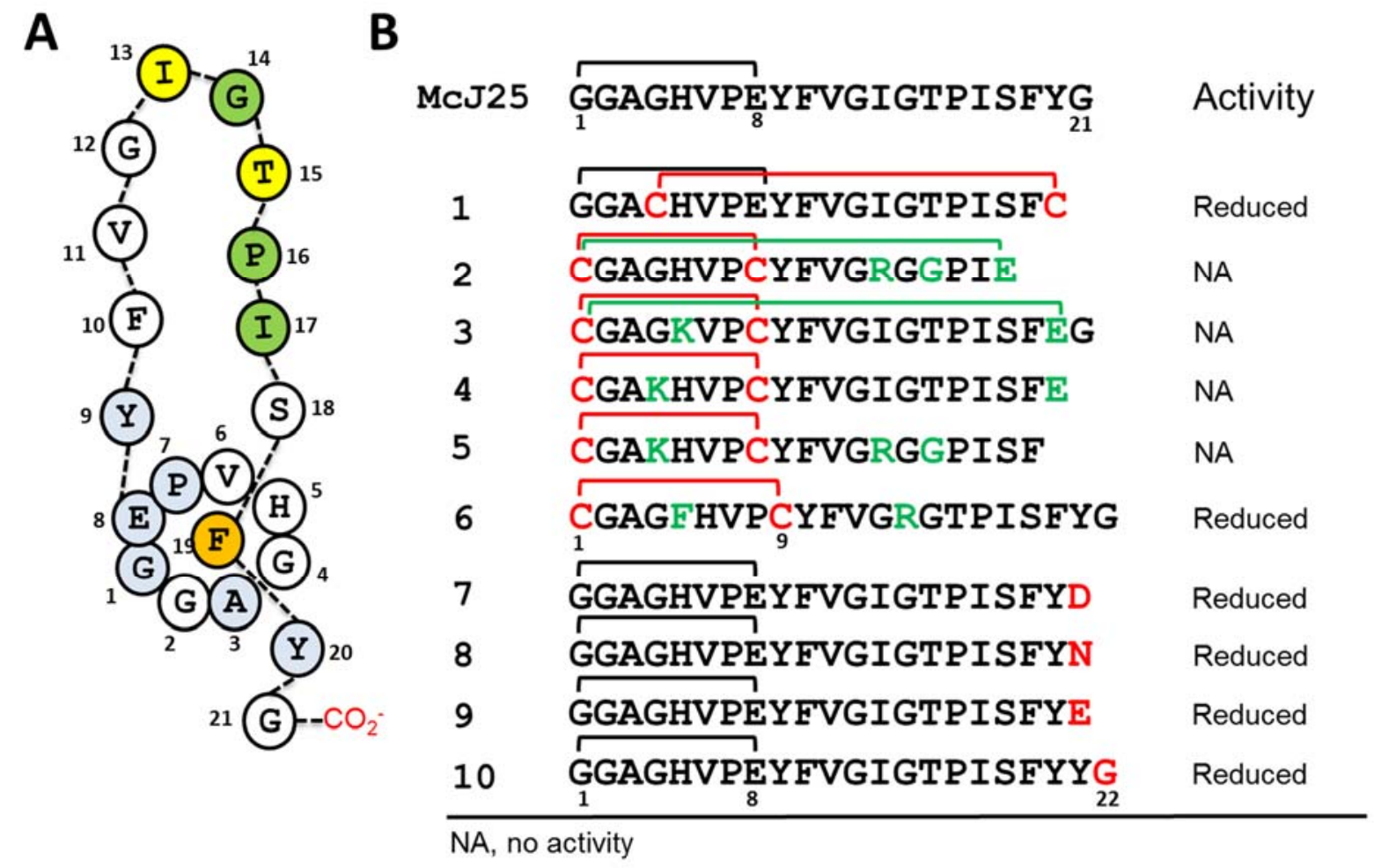

Fig. (4). Diverse analogues of MccJ25. (A) MccJ25 cartoon structure with different colour represents the effect of substitution over antibacterial activity. blue; almost complete loss of antibacterial activity for any studied substitution, white; approximately $70 \%$ reduction observed for all studied analogues; green represents the positions where substitution showed approximately comparable or maintenance of more than $70 \%$ of the peptide activity and yellow; where substitution of approximately all different amino acids show activity similar to or higher than the native McJ25. (B) Analogues of MccJ25 where elongation, deletion, and cyclic replacements in the peptide sequence effects biological activity. Analogues 1-6 are synthetic peptides, whereas analogues 7-10 are generated by site-directed mutagenesis. 
genetically designed 381 analogues of $\mathrm{J} 25$ by substituting each amino acid (from 1-7 and 9-21) with different amino acids [67]. They observed that certain amino acid residues are essential and play key role in the peptide biosynthesis, stability of the analogues, inhibition of the RNA polymerase and also in permeation of the target cell membrane. For instance, positions 1, 2 and 8 (Gly1, Gly2 and Glu8) are indispensable for production of stable analogues, position 9 (Tyr9) is important for RNA polymerase inhibition, and positions 4, 7, 10, 19 and 20 (Gly4, Pro7, Phe10, Phe19 and Tyr20) are essential for growth inhibition [67]. Altogether, these reports suggest that loop is essential for cell permeation, while the macrolactam ring and certain positions within the ring and adjacent to the ring along with the tail stabilizing position are essential for growth inhibition and/or RNA polymerase inhibition.

To further conclude the extent of tolerance of modification of different segments of MccJ25, Link's group from Princeton University derived more than 100 active analogues through site directed mutagenesis with concurrent multiple substitutions in loop/tail as well as the macrolactam ring [68]. As we have seen from the earlier reports of Pavlova et al. the loop plays crucial role in permeation across cell membrane (interaction with outer membrane receptor FhuA for their import) [67]; however Link's group found that along with the loop, some positions of the ring are also crucial for this interaction. It has also been validated that the loop or the tail is more tolerable for modifications than the ring with respect to the antibacterial properties [68]. 
In order to understand the importance of lasso topology in antibacterial activity, our group designed synthetic analogues of MccJ25 by introducing disulphide bridge to replace the amide bond ring, increasing the size of ring, end to end cyclization, or substitution of certain residues [69]. Two synthetic peptides (1 and 6, Fig 4b) active against Salmonella newport were derived from the sequence of MccJ25 in this study. One analogue contained an additional disulphide bridge between C-terminus and middle of lactam ring and the other was with amide bond replaced with disulphide ring. Both displayed about 25-50 fold reduced activity compared to MccJ25. Additionally, these synthetic analogues did not fold into a lasso conformation suggesting that the topology could be the reason behind the significant reduction in the activity [69]. Similar to MccJ25, the synthetic analogues displayed minimal toxicity toward mammalian cells and were found to act specifically on Gram-negative bacterial strains. Among other reports, Ducasse et al. provided insight on different positions of ring and hairpin loop of McJ25 for maintaining the topology of lasso structure and their importance in antibacterial activity. The authors found that Tyr20 plays crucial role in maintaining lasso topology. In addition, Gly21 is also important for stabilizing threaded tail across the ring for the lasso topology [70]. Increasing lariat or ring size to 9 residues by incorporating extra amino acids or deletion of C-terminal Gly21, turn the lasso topology into branched cyclic, which led to a complete loss of activity [70]. Substitution of the C-terminal Gly21 with Asn, Asp or Glu, or increasing the length of the tail by Gly22 does not terminate peptide activity, however, the antibacterial activity was reduced (Fig 4b). 
Piscota et al developed substituted analogues of MccJ25 using unnatural amino acids at positions Val6, Ile13, Phe10 and Phe19 through site directed mutagenesis [71]. Previous studies showed that substitution of Phe10 and Phe19 even by natural amino acids abolished antibacterial activity either completely or multiple folds; however, this study reported that substitution with non-canonical amino acids at stated position do not show any detrimental effect over activity. These data suggest that most likely the topology plays a crucial role in maintaining the activity [71], and opens the door toward production of new variants of $\mathrm{MccJ} 25$ with a potential for broad spectrum and potent anti-bacterial.

It is clear from the SAR studies that MccJ25 and analogues execute their function through inhibition of RNA polymerase and/or respiratory chain of targeted bacterial cells. In order to exhibit these intracellular activities the peptide gets access through exploiting one of ferric siderophore complex receptor FhuA of closely related Entrobacteriaceae. Lately, Mathavan et al successfully developed and solved crystal structure of the complex of FhuA with MccJ25 [72]. In the study they have elucidated the role of ring by substitution with charged or uncharged amino acids and role of loop in establishing the proper interaction for import of $\mathrm{J} 25$, and functionally validated these through competition experiment with T5 phage which utilize same receptor for injecting DNA material into bacterial cells. The structure activity relationships for MccJ25 from a large number of reports suggest lasso topology has a great potential for developing novel antimicrobial agents. 


\subsection{Microcin B17 (MccB17)}

MccB17, a narrow spectrum antimicrobial peptide, exhibits antibacterial activity through utilizing receptor mediated intracellular targeting process [73]. In general, most of the narrow spectrum and potent antimicrobial peptides of bacterial origin use some specific membrane receptor protein or essential nutrient channel for permeation across the membrane. MccB17 uses the outer membrane protein poring OmpF and inner membrane SmbA for permeation across the cell membrane. MccB17 exhibits potent activity against a wide range of Gram-negative bacteria like E. coli, Salmonella, Pseudomonas and Klebsiella by inhibiting the replication through down regulation of enzymatic activity of type II topoisomerase (mainly known as DNA gyrase) [73-77]. Initially it was discovered as ribosomally synthesised peptide antibiotic requiring at least four genes but molecular mass observed for the peptide was lower than expected from DNA sequence. The peptide undergoes extensive posttranslational modification by seven cluster gene mcb A to $\mathrm{G}$ from the E. coli harboring conjugative plasmid pRYC17 (also known as pMccB17) [78]. The early chemical analysis report indicated that many residues of the peptide are posttranslationally modified, however, Jung's group in 1993 and Kolter's group in 1994 highlighted that the peptide undergo exceptional posttranslational modification involving backbone and generation of four thiazole and four oxazole rings by condensation and dehydrogenation of four Ser, four Cys and six Gly residues [78, 79]. Later on, clearer image of previous findings about posttranslational modification and unusual oxazole, thiazole and bis-heterocyclic (oxathiazole and thiaoxazole) structure formation in the backbone of the peptide were given. The authors also alleged that this 
bis-hetrocyclic structure plays a crucial role in gyrase inhibition mediated antibacterial activity $[80,81]$.

After the discovery of MccB17 in 1976 by Asensio et al. [82], Moreno group in 1985 identified that this peptide exhibit antibacterial activity through inhibition of DNA replication by down regulating DNA gyrase activity specifically targeting $\beta$-subunit of DNA gyrase [83]. A non-ribosomally derived peptide anticancer agent bleomycin contains bis-homocyclic thiazole ring, executes anticancer activity through directly binding with DNA and producing double strand break. The structural component bishomocycle of thiazole ring of bleomycin provided a great derive to dig out the role of similar structural component of B17 in gyrase mediated antibacterial activity [84].

In earlier reports of B17 for structural and posttranslational modification elucidation, it was found that substitution of Gly24 with Gln reduced the antibacterial activity of the peptide. It was proposed that the cause for reduced activity is due to the deletion of fourth thiazole ring, which further hindered the cyclization at downstream residues. In other study, the substitution of all four oxazole rings with thiazoles completely abolished the activity. Furthermore, to determine the role of bisheterocylic structure of thiazole and oxazole ring of B17 in inhibition of DNA gyrase activity in vitro and antibacterial activity, several analogues derived through site directed mutagenesis by Walsh group and collaborators were developed [85]. The sequence of B17 contains two bisheterocycle of thiazole and oxazole, one toward the $\mathrm{N}$-terminus designated as site A (Oxazole-Thiazole) and another towards the C-terminus called site B (Thiazole-Oxazole) as shown in Fig. 
(5). Several modification of these heterocyclic structures were attempted, namely, site A $\mathrm{G}_{13}-\mathrm{S}_{14-} \mathrm{C}_{15}$ (A GSC) modified to $\mathrm{A} \mathrm{G}_{13}-\mathrm{C}_{14}-\mathrm{C}_{15}$ (A GCC), G13-S $14-\mathrm{S}_{15}$ (A GSS) and G13$\mathrm{G}_{14}-\mathrm{C}_{15}$ (A GGC), and site B G28- $\mathrm{C}_{29}-\mathrm{S}_{30}$ (B GCS) modified to B $\mathrm{G}_{28}-\mathrm{C}_{29}-\mathrm{C}_{30}$ (B GCC), $\mathrm{G}_{28}-\mathrm{S}_{29}-\mathrm{C}_{30},(B \mathrm{GSC}), \mathrm{G}_{28}-\mathrm{G}_{29}-\mathrm{S}_{30}$ (B GGS), G ${ }_{28}-\mathrm{G}_{29}-\mathrm{C}_{30}\left(\mathrm{~B}\right.$ GGC) and $\mathrm{G}_{28}-\mathrm{G}_{29}-\mathrm{G}_{30}$ (B

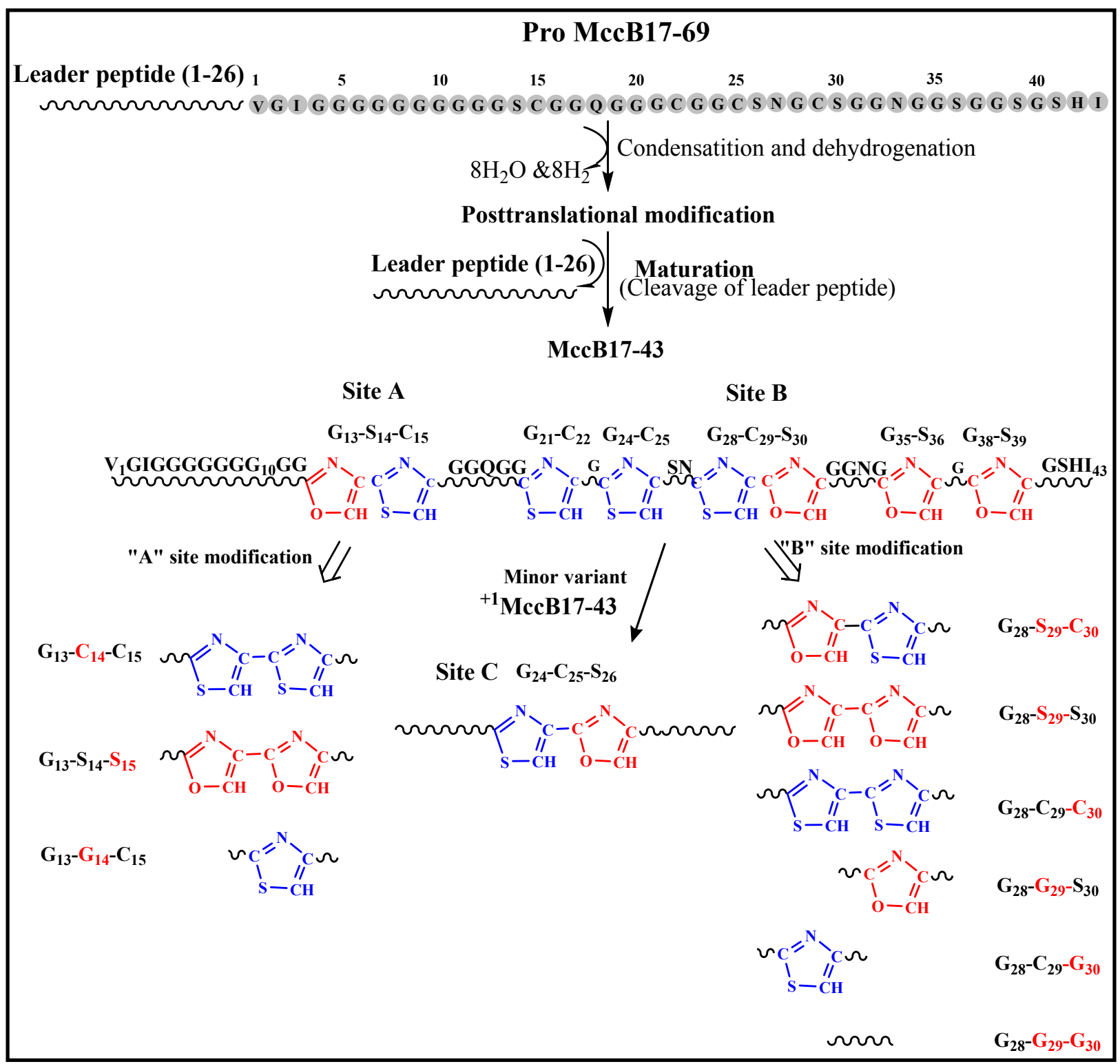

Fig. (5). Structure of MccB17 and analogues. The bis-heterocyclic sites that were altered in the MccB17 analogues are labeled A and B, and the modifications made are shown (drawn) below each site. 
GGG). Through in vitro gyrase inhibition or determination of the extent of cleaved double stranded DNA assay and antibacterial efficacy, it was observed that modification of site B led to drastic decrease in activity. Modifications like site B "Thiazole-Oxazole" modified to "Oxazole-Thiazole", "Oxazole-oxazole" or "Thiazole-Thiazole" observed more than $70 \%$ decrease in antibacterial activity. However, when site B modified into single ring (Thiazole or Oxazole) or no ring reduced the activity was more than $90 \%$. While site A "Oxazole-Thiazole" modification to "Thiazole-Thiazole" did not show any effect on the antibacterial activity, the modification to "Oxazole-Oxazole" reduced activity by almost $30 \%$ [85]. Furthermore, a natural minor variant " ${ }^{~} \mathrm{MccB} 17-43$ " (9 ring peptide) shows more potency in vitro as well as in vivo than the major natural forms of B17 “MccB17-43 (8 ring peptide).

Asensio et al. found that peptide B17 loses activity at extreme $\mathrm{pH}$ (1 and 12), by treatment with pronase and subtilisin but remains active even after boiling at $100{ }^{\circ} \mathrm{C}$ for 30 mins [82]. Later Parks et al. found that at high pH Asn53 and Asn59 deamidate into aspartate and resultantly lose activity in vitro as well as in vivo [86]. In a molecular modeling study, the authors found that these residues reside on surface and deamidation to aspartate generates negative charge which may be a probable trigger for unfavorable interaction with DNA gyrase complex [86]. Thompson et al. degraded B17 chemically and enzymatically, and found that the chemically degraded mixture shows inhibition towards supercoiling and relaxation activity of gyrase, however, the ability to stabilize DNA-gyrase complex was lost [87]. The enzymatically cleaved mixture on the other 
hand, showed all three in vitro activities. Another group tried mutations in B17 with lysine at different positions (to cleave at specific position with trypsin) as well as introduced stop codon to produce multiple analogues with truncated $\mathrm{N}$-terminus and Cterminus peptides (Fig 6). Deletion of one, two or three amino acids from the C-terminus dropped stabilization of cleaved DNA gyrase complex abruptly or completely, whereas truncation of N-terminus 8-11 amino acid or synthetic analogue Mcc [Gly46-Ile69] showed activity similar to full length B17. The same group also synthesized combination of several $\mathrm{N}$-terminal tail (11 amino acid tail of $\mathrm{N}$-terminus) truncated, $\mathrm{A}$ and $\mathrm{C}$ site mutated analogues to find the role and importance of sites $\mathrm{A}, \mathrm{C}$ and the $\mathrm{N}$-terminus. The truncation of N-terminus tail up to 20 -amino acids did not exhibit significant effect on DNA cleavage activity except one analogue. This analogue showed 2-3 fold higher activity than the full length sequence. Modification of the A and C sites in full-length peptide revealed approximately $50 \%$ decrease in activity. In contrast in vivo study (antibacterial efficacy) for all the analogues, except the above mentioned tail truncated analogue, showed partial or no activity at all. Only A and/or C site modified analogues showed 50-70\% activity of the wild-type peptide. In 2014 Severinov group stepped up to find the role of C-terminus, specially, the last three amino acids on in vitro DNA cleavage (cleaved DNA Gyrase complex stabilization) and in vivo antibacterial efficacy [88]. Through site-directed mutagenesis, various C-terminus truncated or substituted (especially after two oxazole rings of B site) analogues were derived. Similar to previous results, deletion of even one amino acid of C-terminus showed in vitro and in vivo detrimental effect toward peptide activity [88]. 


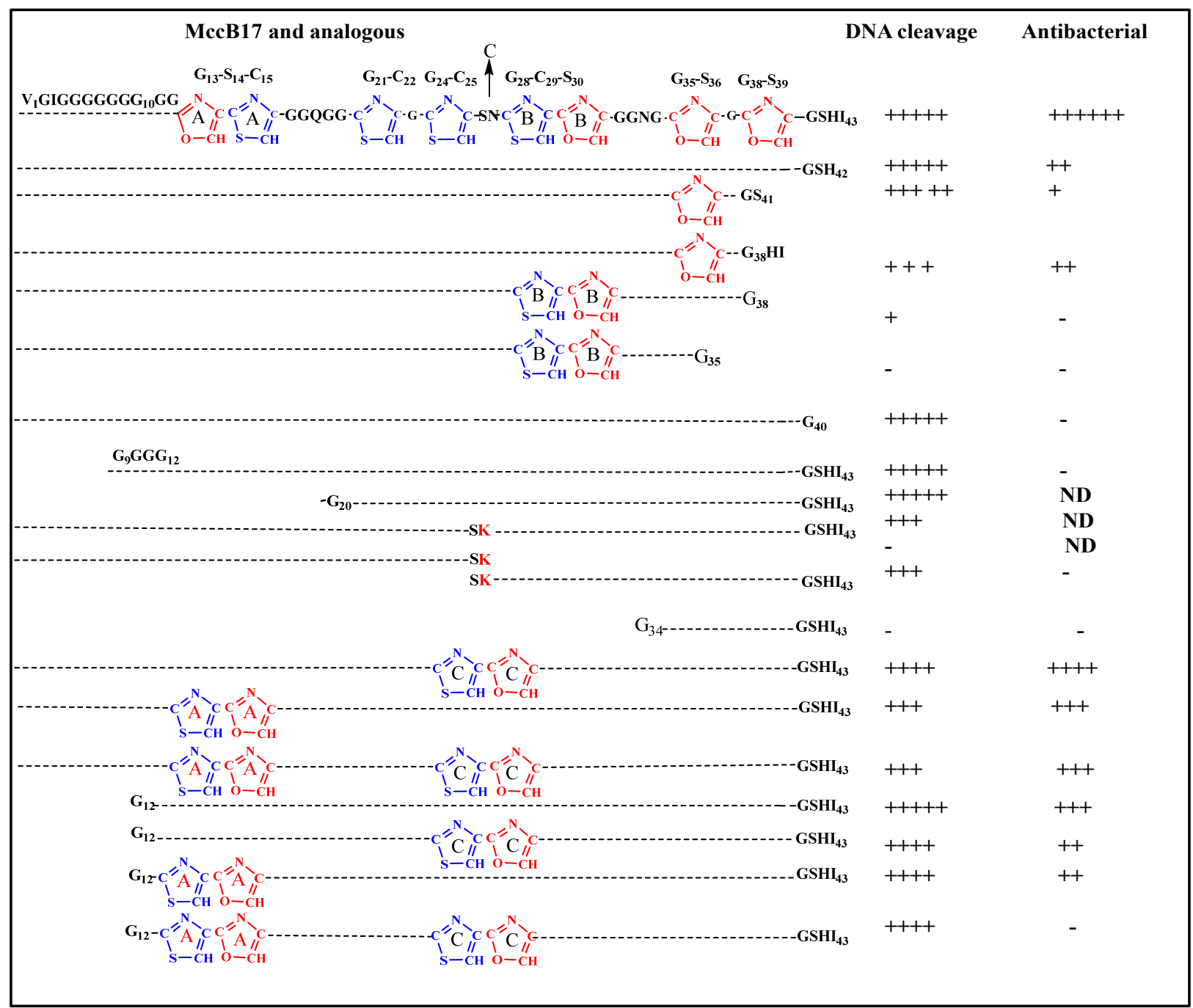

Fig. (6). DNA cleavage (Cleaved DNA-Gyrase complex stabilization) and antibacterial activity of MccB17 and its analogues from different study [88]. A, B and C are sites of bisheterocyclic structure and modification.

\subsection{Microcin C (MccC)}

$\mathrm{MccC}$ is a naturally occurring potent antimicrobial peptide produced by several strains of E. coli. It consists of a 7-mer peptide with a formylated N-terminal methionine and a Cterminal aspartate whose $\alpha$-carboxyl group is covalently attached to adenosine through an $\mathrm{N}$-acyl phosphoramide bond $[89,90]$. Peptide $\mathrm{MccC}$ acts as a prodrug; it is digested first 
inside the target cells by peptide deformylase which removes the N-terminal formyl group, followed by several aminopeptidases that remove the small peptide portion releasing the active processed moiety, aspartyl-phosphoramidate adenosine or processed MccC (Fig. 7A) [89]. This active compound is a mimic of aspartyl adenylate, and a very potent inhibitor of aspartyl-tRNA synthetase (AspRS), which locks protein synthesis at the translation step. It is believed that $\mathrm{MccC}$ penetrates the outer membrane of $E$. coli mostly through the OmpF porin, but also through other, yet-unidentified transport systems. The peptide then penetrates the inner-membrane via the $\mathrm{ABC}$ transporter YejABEF, which is the only transporter used for transporting microcin into the cytoplasm $[91,92]$.

The unique mode of action of $\mathrm{MccC}$, for which the final processing steps occur inside the target bacteria, has made it an attractive model for elaborating analogues, targeting other aminoacyl-tRNA synthetases. A series of $\mathrm{MccC}$ analogues, which retained the initial Trojan horse mechanism of antibacterial activity displayed by the natural $\mathrm{MccC}$, have been reported. In order to prove the major impact of the N-terminal formyl moiety in the peptide biological activity, a study by Kazakov et al. showed that derivatization of the formyl group at the N-terminal methionine effects the biological activity and decreases the growth of inhibition far below than that was displayed by the native MccC peptide (Fig 7B) [93]. 

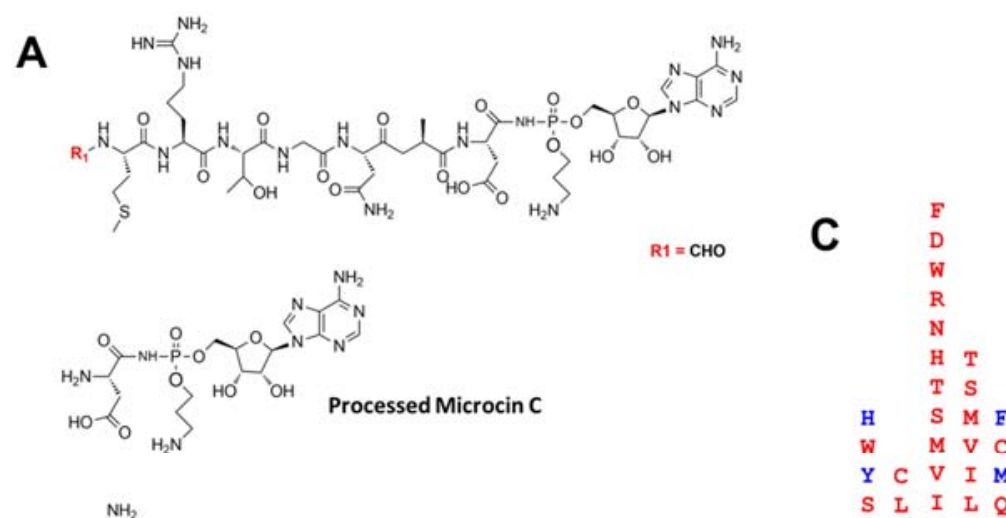

B

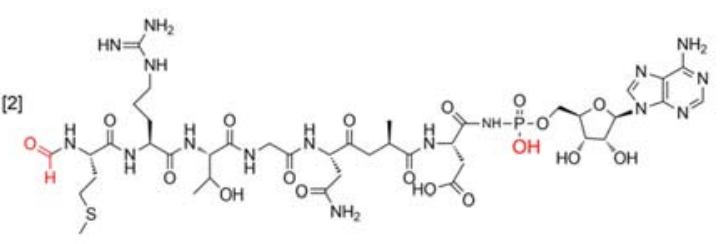

$S$ I $I$ I $Q$

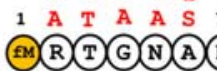

L A L W L A

I I C G I

V V P C

M M Y P T V

T $S$ K $F$ W $M$

G W W $Y$ Y $G$ S

C $\quad G \quad$ H $\quad$ P $\quad$ T

P P Q Y W

F $F \quad$ K H G

[3]

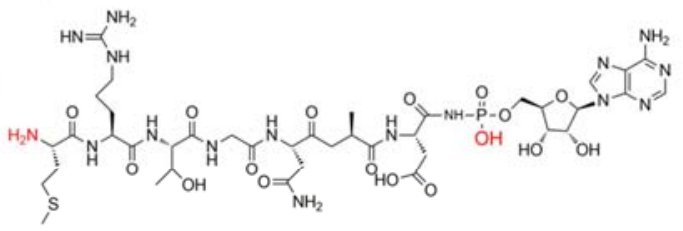

[4]

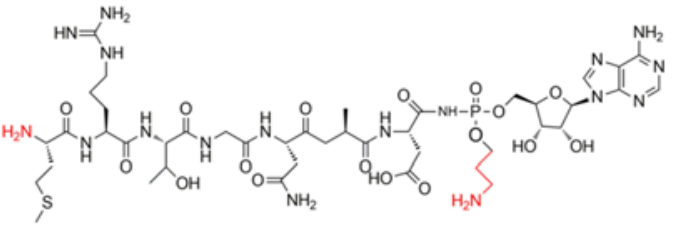

N $\quad Y \quad R \quad N \quad C$

Q H D L P

K N E R F

E $Q \quad$ E Y

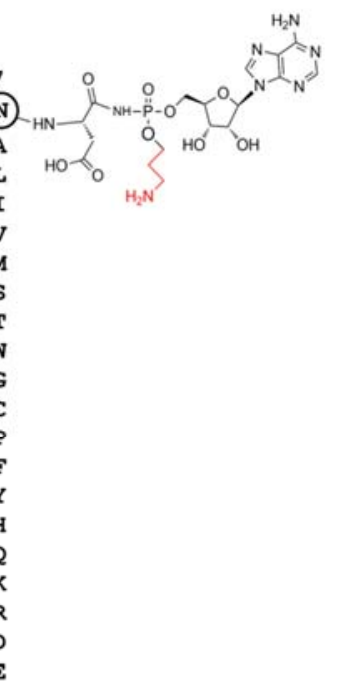

D

[1]

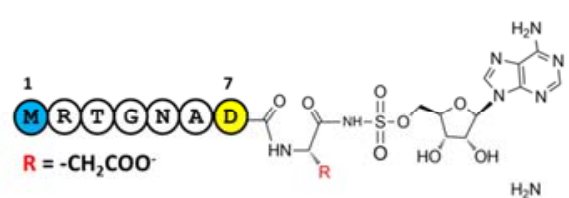

E

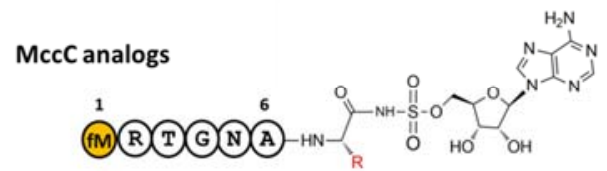

[2]

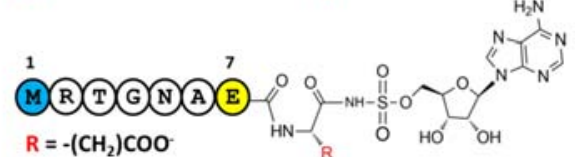

[3]

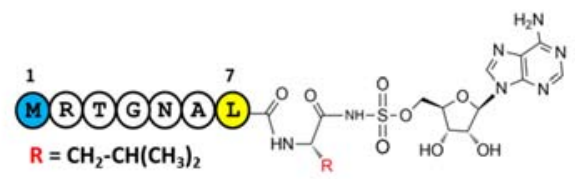

Fig. (7). (A) Structures of Microcin $\mathrm{C}$ or $\mathrm{MccC}(\mathrm{R} 1=\mathrm{CHO})$, the deformylated variant $(\mathrm{R} 1=\mathrm{H})$ and the processed MccC. (B) Structures of different MccC derivatives. Deformylation of the N-terminal decreases biological activity of the peptide. Analogues 3 and 4 displayed much lower activity than the native peptide $(\mathrm{MccC}, \mathrm{R} 1=\mathrm{CHO})$ and analogue 2. (C) SARs of more than 100 mutants of MccC. The native MccC is shown as mix of encoded circles and chemical structure. Mutations are revealed in colored letters. 
The mature MccC produced is shown above the native, while the immature $\mathrm{MccC}$ is displayed below the native sequence. Substitutions indicated by a red color resulted in growth inhibition zones that were comparable to that produced by cells producing nativetype MccC. Cells producing MccC with substitutions indicated by a blue color did not produce biological activity by lawn assays. (D) Three synthetic analogues of $\mathrm{MccC}$, where the mutation has taken place at residue seven; sulfamoyl linker is used instead of a phosphoramidate linker, and N-terminal formyl moiety has been cleaved. (E) Various analogues of $\mathrm{MccC}$ as shown.

The site-directed mutagenesis were applied to $\mathrm{MccC}$ gene and a large set of $\mathrm{MccC}$ analogues were produced [94]. As seen in Fig 7C, among a 114 substitutions in the lead peptide, only 28 substitutions did not significantly alter the bioactivity of the peptide. Four additional substitutions did not affect $\mathrm{MccC}$ maturation but seemed to interfere with uptake or processing. Thus, approximately $30 \%$ of the substitutions in the peptide resulted in functional or partially functional mature microcin. The study showed a list of acceptable substitutions in the $\mathrm{MccC}$ precursor peptide that could facilitate the chemical synthesis of microcins with altered specificity allowing to select functional peptide sequences that can be efficiently conjugated with the nucleotide moiety of MccC.

A study by Vijver et al. reported three analogues for $\mathrm{MccC}$ that were synthesized to have different amino acids at the seventh position of the peptide [95]. These analogues have Asp, Glu, or Leu at the position seven. The analogues lack the N-terminal formyl moiety and have a sulfamoyl linker instead of a phosphoramidate linker and unlike the native $\mathrm{MccC}$ the $O$-aminopropyl group was left out in these analogues (Fig 7D). In contrast to other studies, these analogues proved to be active and worked by the same mechanism as the wild type $\mathrm{MccC}$ despite lacking the $\mathrm{N}$-terminal formyl group [95]. The finding 
suggested that the analogues were internalized by the YejABEF peptide transporter and metabolized by three broad-specificity peptidases PepA, B and N.

Following new synthetic strategies, the same group reported development of new synthetic analogues of $\mathrm{MccC}$ to improve the yield of synthetic peptides and extend the range of MccC-like compounds. Although new series of MccC analogues were developed and synthesized with better yields in comparison to previous protocols, the biological activities of the peptides were in the same range as observed for the native $\operatorname{MccC}($ Fig 7E) [96].

Despite potent antibacterial activity of microcins in vitro and in vivo, these AMPs are not yet approved for clinical applications. Apart of other studies, the pharmacokinetic and in vivo properties of microcins need to be optimized for clinical use. SARs studies certainly highlight the potential of these AMPs and should encourage the development of these AMPs into novel antibiotics with greater activities toward pathogenic and resistant bacteria.

\section{CLASS II BACTERIOCINS}

Class II bacteriocins are non-lanthionine containing bacteriocins that are not exposed to extensive post translational modifications (Table 1). In general, they are divided into several subclasses, class IIa, class IIb (the two-peptide bacteriocins), class IIc (cyclic bacteriocins), class IId and IIe $[1,24,97]$. Class IIa, which is also known as pediocin-like bacteriocins, consists of the anti-listerial one-peptide with one or two disulfide bonds and 
a conservative N-terminal motif $[98,99]$. The class IIb bacteriocins, also known as the two-peptide bacteriocins, contain two different peptides that achieve optimal antibacterial activity by the presence of two peptides together at equivalent concentrations $[100,101]$. Class IIc are the cyclic peptides, where the $\mathrm{N}$ and $\mathrm{C}$-termini are covalently linked resulting in a cyclic structure. Class IId bacteriocins, also referred to as the linear nonpediocin-like peptide bacteriocins, show no sequence similarity to the pediocin like bacteriocins [24, 97]. Finally class IIe are similar to class IId but with more modifications like siderophore conjugation.

In this review we focus mainly on the recent structural-activity relationship of class II bacteriocins produced by lactic acid bacteria and their latest developed analogues. In particular we will pay attention to the most well characterized bacteriocins that were highlighted in Table 1, namely, Pediocin PA-1, Leucocin A, and Sakacin P.

\subsection{Class IIa Bacteriocins}

\section{Pediocin PA-1}

Pediocin PA-1 is one of the well-understood bacteriocin that exhibits inhibitory activity against foodborne Listeria monocytogenes at nM range of concentrations [102]. The structural functional relationship of pediocin PA-1 was evaluated by generation of several mutants either by chemical synthesis or by the use of site-directed mutagenesis [97]. To mention some, a study by Tominaga et al. showed the essential residues for maintaining the bioactivity of pediocin and the structure function relationship using a technique termed NNK scanning [103]. In their study, each residue of the native codon was 
replaced with the NNK triplet oligonucleotide using the NNK scan and the 35 generated peptide mutations were examined for antimicrobial activities. The activity was retained by almost all analogues harboring mutations at $\mathrm{K} 1, \mathrm{~T} 8, \mathrm{G} 10, \mathrm{~S} 13, \mathrm{G} 19, \mathrm{~N} 28$, and N41, while the activity was completely abolished by many of the mutations at residues Y2, G6, $\mathrm{C} 9, \mathrm{C} 14, \mathrm{C} 24, \mathrm{~W} 33, \mathrm{G} 37$, and $\mathrm{C} 44$, signifying that these residues are critical in the peptide. While 14 substitutions were inactive at G6, 11 replacements were inactive at position C14 [103].

In a recent study, nine mutants of pediocin PA-1 were generated with a variety of substitutions and increasing number of positively charged residues. There was two-fold increase in the activity of some generated analogues [104]. The bactericidal activity of mutant 0K was equal to that observed for the wild-type Pediocin PA-1 (Fig 8). The analogue S13K was somewhat more potent than the native Pediocin PA-1, indicating that additional charged residues at position 13 has a positive impact on activity. Moreover, the mutant $0 \mathrm{~K}+\mathrm{S} 13 \mathrm{~K}$ showed more potency than the mutant S13K, indicating the significant role of lysine at the $\mathrm{N}$-terminus in receptor recognition and binding. Contrary, other mutants such as, $2 \mathrm{~K}, \mathrm{G} 10 \mathrm{~K}, 2 \mathrm{~K}+\mathrm{S} 13 \mathrm{~K}, 0 \mathrm{~K}+2 \mathrm{~K}+\mathrm{S} 13 \mathrm{~K}$ and $0 \mathrm{~K}+2 \mathrm{~K}+\mathrm{G} 10 \mathrm{~K}$ had abridged pediocin potency. The finding suggested that the electrostatic interactions between the peptide and the target bacterial cells are drastically affected by insertion of additional cationic amino acid residues [104]. 


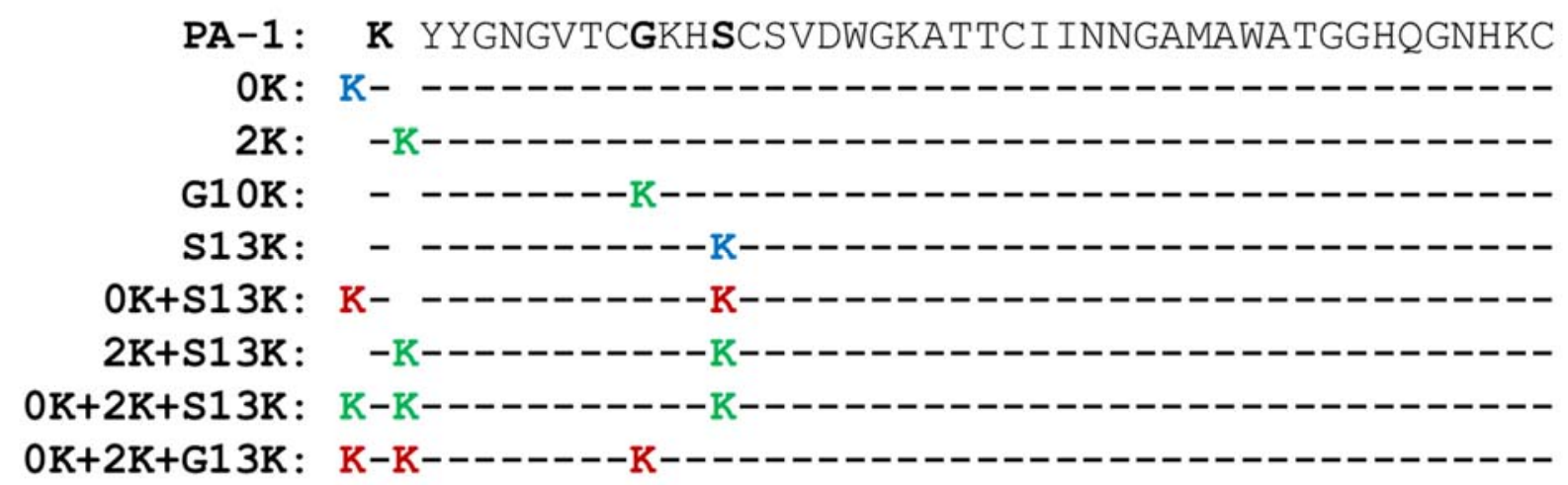

Fig. (8). Variants of pediocin PA-1 with substitution with charges lysine residue(s). Residues in green color denote almost similar activity, blue colored residues represent moderate activity, and residues in red color represent loss of activity.

The structure activity relationship of pediocin-like bacteriocins, suggested that the $\mathrm{N}$ - and C-terminus of bacteriocins may function independently to some extent. Specific hybrid bacteriocins from $\mathrm{N}$ - and $\mathrm{C}$-terminal regions of different Pediocin-like bacteriocins revealed that the $\mathrm{C}$-terminus half of these bacteriocins are important for the target cell specificity, indicating that the C-terminal of pediocin must interact with an entity in the surface membrane of the target cells [105]. In agreement with this finding, a similar study, where the C-terminus of pediocin exposed to substitutions by mutagenesis, showed that mutated peptide differ from the parental pediocin in their target specificity [106]. Likewise, a previous study by Fimland G et al. showed that a 15 -mer peptide fragment derived from pediocin PA-1 (from residue 20 to residue 34) was able to inhibit the biological activity of pediocin [107]. Although the derived-fragment showed abolishment of pediocin bactericidal activity and with less extent to enterocin, it did not display any inhibition to other pediocin-like bacteriocins. It's been suggested that a competitive interference with the pediocin target entity on the bacterial cell membrane is behind this effect of inhibition. One protein that appears to be involved in such an interaction is the 
membrane-associated mannose phosphotransferase system permease, which is found in the surface membrane of the targeted bacterial cells. Recently, two hybrid bacteriocins, enterocin E50-52/pediocin PA-1 and pediocin PA-1/enterocin E50-52 designed by switching the $\mathrm{C}$ and $\mathrm{N}$ terminus domains, showed reduced MICs in comparison to those of their natural counterparts. [108] .

Several investigations were performed in the last decade with pediocin PA-1 and a majority have been reviewed elsewhere [98, 109-111]. Despite the fact that pediocin PA1 has been empirically used for many years, most of the current knowledge on pediocin PA-1 that were generated is not enough to translate it to a therapeutic product. Pediocin PA-1 has been the subject of considerable interest for many years. However, there are still many aspects that need further research and investigation. The structure and mode of action are still far from completely elucidated. Establishing the relationships between pediocin structure and its biological activity is of particular interest because this knowledge may enable to boost its activity and generate understanding of the mechanisms of bacterial resistance to the peptide. We believe peptide engineering, genetically and/or by chemical synthesis would lead to the development of new AMPs with improved properties based on some features of the pediocin PA-1 antimicrobial peptide.

\section{Leucocin A (LeuA)}

LeuA is another potent AMP from class IIa bacteriocins active against Listeria monocytogenes in the $\mathrm{nM}$ range (MIC $37 \mathrm{nM}$ ) [112]. Like pediocin PA-1, LeuA consists 
of C-terminal amphipathic alpha helix and $\mathrm{N}$-terminal with $\beta$-sheet-like structure beside the conservative YGNGV motif. LeuA is 37 residues long and features one disulfide bond between C9 and C14 (Fig 9a). Historically, LeuA was first isolated from Leuconostoc gelidum UAL 187 by Hastings et al. in 1991 [113] and the first structure elucidation and confirmation was performed by Vederas et al. in 1997 [114]. Due to its potent activity, LeuA has received considerable attention and the SARs are still a popular topic for the ongoing research.

One of the first analogues of LeuA was an all D-amino acid enantiomeric peptide, where the entire peptide was made from D-amino acids instead of L-amino acids [115]. The DLeuA was not active demonstrating involvement of a chiral docking molecule for the peptide mechanism of action. Year later, a mutagenesis of $\mathrm{mpt}$ operon in Listeria monocytogenes [116], generated a peptide-resistant bacteria enabling scientists to find a particular enzyme-domain as a potential receptor for class IIa bacteriocins. The findings were confirmed further by other studies, where all suggested that a particular domain/or subunit of mannose phosphotransferase system - a receptor that transports sugar through the cytoplasmic membrane and phosphorylates it as it pass into the intracellular system is responsible for the biological activity of peptide, as it serves as a target receptor for class IIa bacteriocins $[117,118]$.

Several hypothesis came in to explain how class IIa bacteriocins exert their biological actions. It is believed that the $\mathrm{C}$ terminal domain of the peptide recognizes a particular target on the surface membrane of the bacteria and then the N-terminus binds the cell 
surface by electrostatic interactions, and together exert the killing action through the pore formation [98]. To understand the significant role of the disulfide bridge of LeuA towards

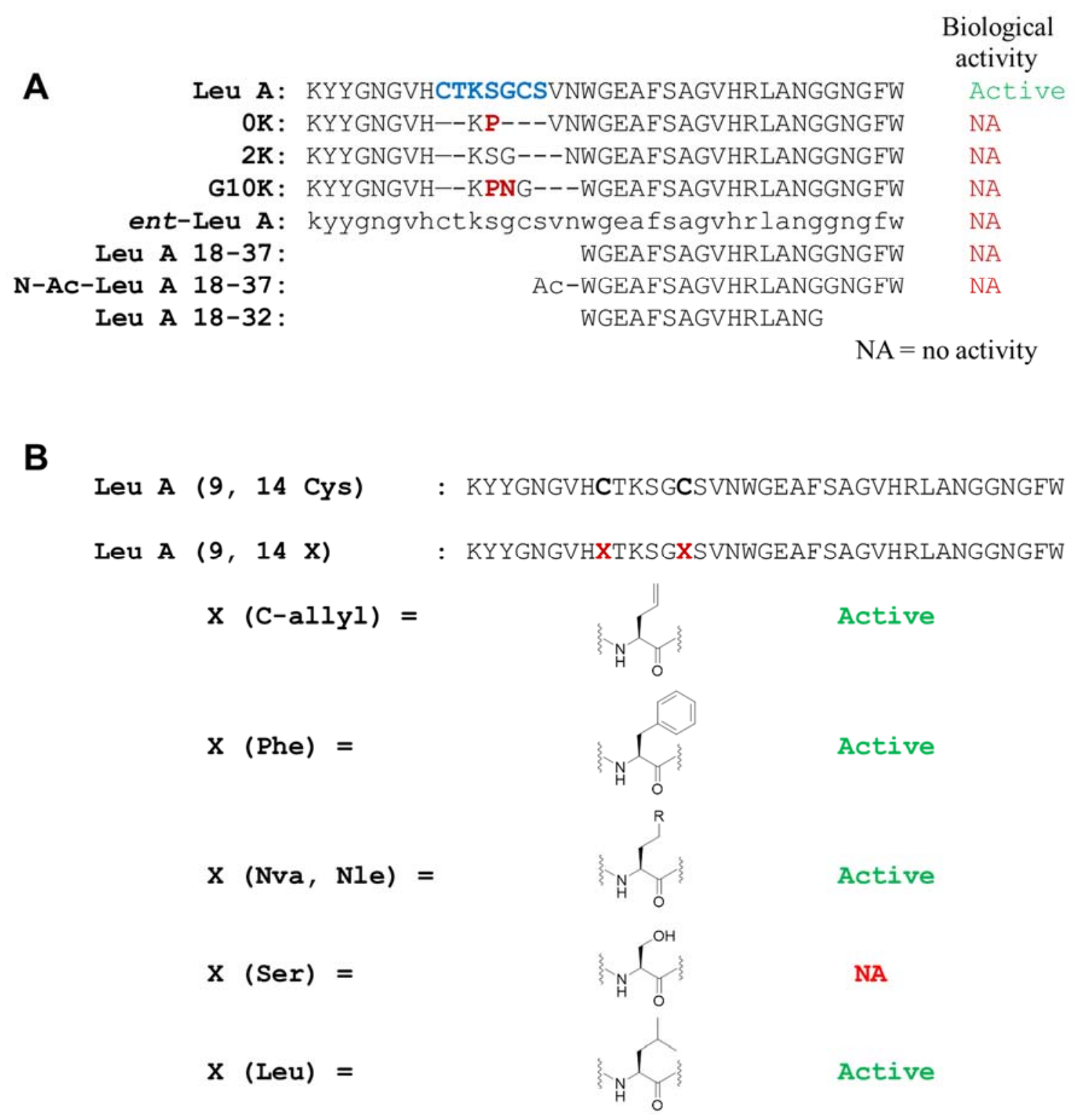

Fig. (9). (A) Structure activity relationship (SAR) of LeuA was studied by addition, deletion and/or amino acid substitutions. Analogues led to loss in the biological activity, indicating importance of the topological structure of LeuA. (B) Leu A analogues made by replacement of the cysteine residues at positions 9 and 14 by other amino acids. While allylglycine, phenylalanine, leucine and norleucine showed comparable activity to the wild-type LeuA, bis-serine abolished activity. 
the bactericidal activity, Vederas et al. synthesized analogues of LeuA, where the disulfide bridge was replaced by carbocyclic moiety (Fig 9b) [119].

Analogue where serine takes place of cysteine 9 and 14 showed no observable activity, whereas replacement of disulfide bridge of LeuA with allylglycine residues without ring formation delivered a LeuA derivative (diallyl-LeuA) with comparable bactericidal activity to the wild-type LeuA. The finding has motivated to synthesize further acyclic analogues of LeuA, wherein disulfide bridge (positions 9 and 14) were replaced by hydrophobic residues such as norvaline, leucine and phenlyalanine [120]. Interestingly these analogues also showed comparable activity to the wild-type LeuA. Apparently the hydrophobic resides hold the loop between residues 9 and 14 close together via hydrophobic interactions and thereby maintain the peptide topological conformation necessary for the activity. By contrast, the bis-serine analogue that shows diminished activity could have insufficient bonding (H-bonding) to maintain the conformational stability of the peptide.

In order to elucidate the structural-functionality of the N-terminal domain of LeuA, our group designed a number of analogues of the LeuA by replacing the $\mathrm{N}$-terminal $\beta$-sheet with shorter $\beta$-turn motifs [112]. The study showed that such replacements eradicate the bactericidal activity of the peptide. One analogue, however, was able to show competitive binding inhibiting the activity of wild-type LeuA. This study suggested the role of proper folding and complete sequence in the activity of class IIa bacteriocins. We also showed for the first time that surface conjugated LeuA (37-residue) shows antibacterial activity 
using a live/dead cell assay, while surface conjugated 24-residue C-terminal fragment of LeuA was not active [121]. [122, 123]. [124]. The results indicate that although the Nterminal region has a vital influence on the activity of the peptide, additional interactions at the $C$ terminus with the receptor must match and contribute to the overall activity. More analogues are under investigation by our group, in particular concerning the potential of LeuA as a recognition element in biosensing devices for detecting Listeria monocytogenes. Likewise, SARs studies of LeuA are ongoing and analogues with higher stability and better potency are under development.

\section{Sakacin P}

Sakacin P is a class IIa bacteriocin produced by Lactobacillus sakei. Like Ped and LeuA, it displays strong activity against certain food-borne pathogens such as Listeria monocytogenes. It consists of 43 amino acids and has a structural similarity to pediocin PA-1 [125]. Few studies have been performed to explore the SAR of sakacin and here we will discuss some of the notable examples. Fimland et al. showed that the introduction of the C-terminal disulfide bridge into sakacin $\mathrm{P}$ particularly broadens the target cell specificity and increases the potency at elevated temperatures. Contrary, removing the Cterminal disulfide bridge in pediocin PA-1 decreases it potency and biological stability [126]. The SARs of the N-terminal domain of class IIa peptides has also been explored through modifications of the N-terminus of sakacin P using site-directed mutagenesis (Fig 10) [127]. To explore the significant role of the charged residues at the N-terminus in binding to the target cells, the residues were substituted with other amino acids and tested for biological activity [127]. Interestingly, in all mutations a decrease in the net 
positive charge causes a reduction (2-15 folds) in peptide potency. The least lethal of these mutations was the replacement of His (H8) by Thr (T8). Interestingly, this mutation did not show lethal effect in potency of the peptide, indicating that the positive charges at position 8 have no major role. The most lethal effect to the peptide's activity was observed during substitution of the positive charges at the $\mathrm{N}$ - and C-terminal ends (K1T, K43T), signifying the importance of the cationic moiety in class IIa bacteriocins [127].

To gain insight on how the $\mathrm{N}$-terminus $\beta$-sheet-like domain in sakacin $\mathrm{P}$ positions itself on the bacterial membrane, substitutions at the conservative motif domain (YGNGV) were designed [128]. The biological activity of the mutant peptides was then investigated

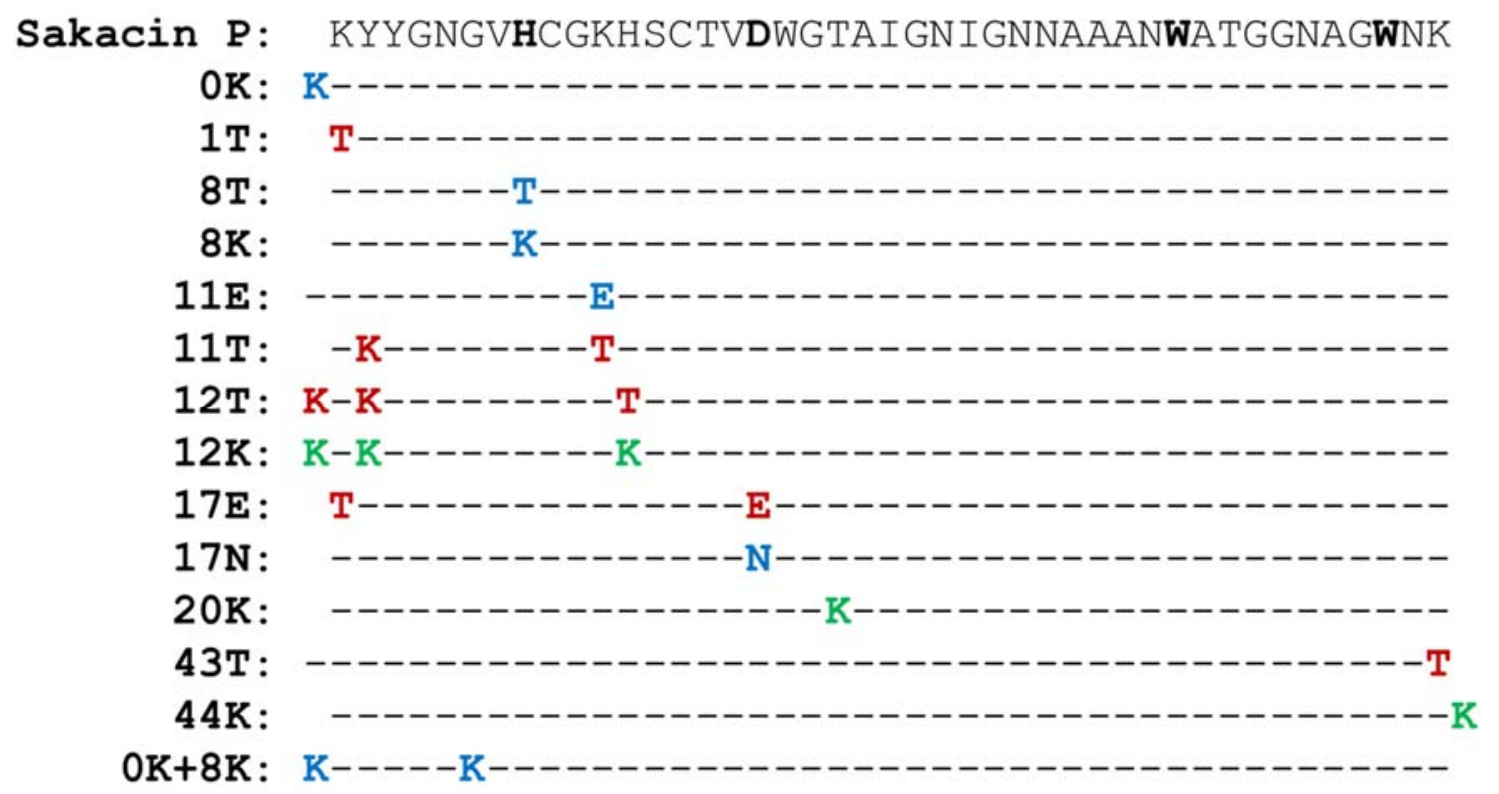

Fig. (10). Site-directed mutagenesis of the N-terminal domain of sakacin P. Green mutations are more active, blue are moderate and red are inactive. 
and the peptide-binding studies were explored using the peptide-liposomes interactions. The results showed association of the N-terminus domain with only anionic liposomes [128]. The study showed also the impact of the electrostatic interaction in penetration of some peptide residues into the liposomes. Further, the biological activity study revealed that the two mutants, $\mathrm{Y} 2 \mathrm{~L}$ and $\mathrm{Y} 3 \mathrm{~L}$ resulted in a 10 -fold reduction in activity, whereas, mutants $\mathrm{Y} 2 \mathrm{~W}, \mathrm{Y} 2 \mathrm{~F}, \mathrm{Y} 3 \mathrm{~W}$ and $\mathrm{Y} 3 \mathrm{~F}$ were tolerated fairly well. Furthermore, the V2I mutant had no effect in the activity. The mutant, G6A was highly detrimental, consistent with G6 being in one of the turns in the $\beta$-sheet-like $\mathrm{N}$-terminal domain. The finding suggested that both the polar amide group on the side chain of N5 and its position in space have significant role in the peptide to be fully active. The study also explained the mechanism and significant role played by hydrophobic residues in positioning the peptide residues on the membranes of the target cells [128].

Throughout the investigational studies of class IIa bacteriocins there is a hope set by these potent peptide to deliver future antibiotics against dangerous pathogens. Class IIa are relatively small peptides (37-48 residues) produced without posttranslational modification or processing making them relatively easy to obtain and modify either by gene expression or using the standard peptide synthesis methods. The high specificity of class IIa bacteriocins against foodborne pathogens, and specifically Listeria monocytogenes makes them ideal candidate to solve issues like foodborne outbreaks with potential in food and pharmaceutical industries.

\subsection{Class IIb Bacteriocins}


Class IIb bacteriocins are two-peptide bacteriocins that consist of two different peptides where optimal antibacterial activity is achieved only by the presence of these peptides together in equal quantities (Table 3) [100, 129, 130]. Majority of class IIb bacteriocins whose mode of action has been investigated render the cell membranes of the target cells permeable to a variety of small molecules [101]. For instance, Lactococcin G (LcnG) targets the cell membrane and allows a variety of monovalent cations to permeabilize such as, $\mathrm{Na}+, \mathrm{K}+, \mathrm{Li}+\mathrm{Rb}+$ and the choline, but not the divalent cations like the $\mathrm{Mg}++$ or the anions like phosphates or the $\mathrm{H}+$. More than 15 peptides of the two-peptide bacteriocins have been identified so far [131]; however, the three-dimensional structure as well as the structural activity relationship of two-peptide (class IIb) bacteriocins are not as well characterized as that of pediocin-like (class-IIa) bacteriocins [100, 131, 132]. As a result, we will limit our SAR discussion in this review to certain peptides of the twopeptide bacteriocins where analogues or mutants were introduced.

Table 3. Structure of some unmodified (class-IIb) two-peptide bacteriocins. The GxxxG and AxxxA motifs are shown in bold.

\begin{tabular}{lll}
\hline \multicolumn{1}{c}{ Peptide } & & \multicolumn{1}{c}{ Sequence } \\
\hline \multirow{2}{*}{ Lactococcin $\mathrm{G}$} & LcnG- $\alpha$ & GTWDDIGQGIGRVAYWVGKAMGNMSDVNQASRINRKKKH \\
& LcnG- $\beta$ & KKWGWLAWVDPAYEFIKGFGKGAIKEGNKDKWKNI \\
Plantaricin E/F & PlnE & FNRGGYNFGKSVRHVVDAIGSVAGIRGILKSIR \\
& PlnF & VFHAYSARGVRNNYKSAVGPADWVISAVRGFIHG \\
Plantaricin J/K & PlnJ & GAWKNFWSSLRKGFYDGEAGRAIRR \\
& PlnK & RRSRKNGIGYAIGYAFGAVERAVLGGSDYNK \\
& & RNKLAYNMGHYAGKATIFGLAAWALLA \\
Plantaricin S & Pls- $\alpha$ & KKKKQSWYAAAGDAIVSFGEGFLNAW \\
\hline
\end{tabular}


As indicated above, the antimicrobial activity of two-peptide bacteriocins is achieved only when two complementary peptides are combined together either from the same peptide bacteriocin or in some cases with two homologues of another peptide bacteriocin. As an example, LcnG showed bactericidal activity at nanomolar level of concentration when combined, but that activity is totally lost when the peptides were tested individually $[131,133]$. No activity were observed even when combined with either the E- or Fpeptide of plantaricin E/F or the J- or K-peptide of plantaricin J/K. [134]. In contrast, higher activity was observed when LcnG was combined with the complementary peptide from (LcnQ) or enterocin 1071, which perhaps is a result of sequence similarities between these peptides $[100,101,135,136]$. The fact that two-peptide bacteriocins function together to display antibacterial activity only when combined clearly indicates that these peptides interact in a particular fashion to form one functional unit and single peptide molecule. This is not surprisingly when we see that the genes encoding the two peptides of two-peptide bacteriocins are located next to each other on the same operon, and that the two peptides are thus produced in nearly equal quantities.

LcnG, plantaricin $\mathrm{E} / \mathrm{F}$ and plantaricin $\mathrm{J} / \mathrm{K}$ are the most well characterized in class $\mathrm{IIb}$ bacteriocins (Table 3). The CD studies showed that these peptides are unstructured in water, and helical formation occurs only when the peptides are exposed to more hydrophobic or membrane-like environment such as trifluoroethanol containing media, micelles or liposomes [137-140]. The results suggested that the peptides of the twopeptide bacteriocins interact in a structural inducing manner upon exposure to the membrane of the target cells. 
Majority of the two-peptide bacteriocins that are explored so far compose of one or two conserved GxxxG motifs in their sequences. These motifs are anticipated to be essential for conjugating the two peptides together. In other words, along with the "GxxxG"-like motifs (AxxxA, SxxxS), the motifs mediate helix-helix interactions between the two complementary peptides of two-peptide bacteriocins and suggested a main role in penetration of the target cell membranes [141-143]. Several mutations have been sited on the GxxxG motif in $\mathrm{LcnG}$, pln $\mathrm{J} / \mathrm{K}$ and $\mathrm{E} / \mathrm{F}$ in order to explore its role in peptide interactions and thereby the effect on the peptide biological activity. Substitution of glycine residues in the GxxxG-motifs of LcnG with larger residues that interfere with close helix-helix contact was extremely unfavourable [144], while replacement of other glycine residues in the peptides was fairly well tolerated. Similarly, mutations of the glycine residues at GxxxG motifs of Pln $\mathrm{J} / \mathrm{K}$ cause loss of the peptide activity, while glycine substitutions at other positions shown no effect on the activity.

Our group explored the structure activity relationships for plantaricin S (Pls) using CD, biological assays and molecular dynamic simulations. The study revealed that the helixhelix alignment of the two Pls peptides and interaction between the conserved motifs are fundamental for interaction with the target cell membrane [145]. The two Pls peptides and five Pls derived fragments were designed and synthesized. CD findings of Pls and the designed fragments showed helical topological structure of the peptides in aqueous 2,2,2trifluoroethanol solutions. The molecular dynamics simulation demonstrated that when 
the two Pls peptides are in antiparallel orientation, the helical motifs interact and align, mediated by strong attraction between the conserved GxxxG/AxxxA motifs [145].

In order to understand structural features that are important for activity and potency of two-peptide bacteriocins, an extensive structure function relationship is required. It is essential that more extensive analyses of how the peptide works, communicate and generate their effect are performed as it is necessary for explaining further details of the mechanism of action of peptides and give more insight on the future of engineering novel antimicrobial peptides. Being small sized linear peptides with no post translational modification, the two-peptide bacteriocins are valuable antimicrobial peptides that can be exploited for rational design of new antibiotics with wide medical and biotechnological applications.

\subsection{Class II Microcins}

Class II microcins are high molecular-mass antimicrobial peptides, ranging from $5-10$ KDa. They have been subdivided into two subclasses, Class IId and IIe [146]. Class II microcins have been less well-studied than class I microcins in regard to their structures, mode of actions and structure-function relationships. In contrast to class IIe, class IId peptides are characterized by disulfide bond with no further post-transitional modifications. While class IId comprises three plasmid-encoded peptides with posttranslationally modification, class IIe consists of chromosome encoded linear microcins that carry a C-terminal siderophore [147, 148]. Fig. (11) shows sequence alignments of the well-studied microcins of class II microcins so far. 
Microcin L (MccL), a 90-residue peptide, is a newly discovered AMP that exhibits strong activity against related bacterial strains, such as Enterobacteriaceae, including Salmonella enterica serovars typhimurium and enteritidis. The partial protein sequencing showed the 40 amino acid residues at the N-terminal of MccL [149] consist of unmodified amino acids [150] Fig. (11). Overall, MccL consists of 90 amino acid residues with a mass of $8,884 \mathrm{KDa}$ and two disulfide bridges [151]. The MccL antibacterial activity relies on its recognition at the cell surface membrane by a specific iron siderophore uptake receptor. The receptor facilitates the peptide passage through the outer membrane following a TonB and energy-dependent pathway [151]. Another microcin, $\mathrm{MccV}$, was first isolated, purified and characterized in 1994 by Kolter and coworkers from E. coli MC4100 harbouring the pHK11 and/or pHK22 plasmid. MccV displays antibacterial activity directed against related Gram-negative bacteria with an MIC of about $0.1 \mathrm{nM}$ against E. coli. $\mathrm{MccV}$ is an 88-residue peptide, without posttranslational modification, which possesses a single disulfide bond connecting Cys76 to Cys87 Fig (11). A preparation of MccV, Procin ${ }^{\circledR}$ (CanBiocin Inc.), has been FDA approved as a probiotic agent that targets specific pathogens of the gastrointestinal tract using $\mathrm{MccV}$ active against pathogenic E. $\operatorname{coli}[152]$. Procin ${ }^{\circledR}$ reduces the incidence and severity of scours in weanling pigs. 
MCC I

Mcc V

Mcc 24

McC E492

McC $\mathrm{H} 47$

MCC L

Mcc V

Mcc 24

Mcc E492

MCC $\mathrm{H} 47$
120

GDVNW---VDVGKTVATNGA ASGRDIAMAIGTLSGQFVAGGIGAAAG AGDPLADPNSQIVRQIMSNAAWGPPL-VPERFRGMAV GETDPNTQLLNDLGNNMAWGAALGAPGGLGSAAL

GGAPATSA

60

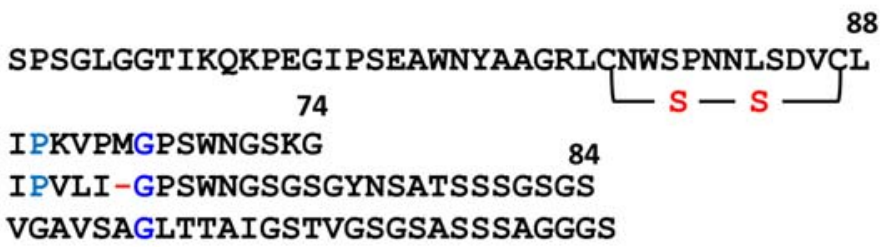

Fig. (11). Sequence of five class II microcins. Peptide sequences were obtained either by Edman degradation (Mcc E492, first 40 AA of Mcc L and 47-first of Mcc V) or presumed from the DNA sequence (Mcc V, Mcc 24 and Mcc H47). Amino acids coloured dark blue or light blue show the impartiality.

Microcin $\mathrm{N}(\mathrm{MccN})$, which is also known as microcin24 or colicin24 (Mcc24), is a bacteriocin produced by the uropathogenic strain E. coli.[150] The peptide has strong antimicrobial activity against pathogenic bacteria, such as E. coli O157:H7, Salmonella enteritidis, and Salmonella enterica serovar typhimurium; however, it does not show antibacterial activity against strains of Campylobacter jejuni and Listeria monocytogenes [153]. As yet, many properties of $\mathrm{MccN}$ have not been characterized, neither SARs have been elucidated [154].

In contrast to class IId microcins, class IIe backbones undergo a bit more post-transitional modifications. In addition to the disulfide bonds, the peptides may carry a siderophore type translational modification. MccE492 is a low molecular mass bacteriocin $(7.9 \mathrm{kDa})$, which was initially produced by Klebsiella pneumoniae RYC492 in 1984 [155]. It acts by forming pores on the membrane of the target bacteria and decreases the membrane 
potential $[155,156]$. Similarly, microcin $\mathrm{H} 47$ is a bactericidal antibiotic produced by a naturally occurring E. coli strain [157]. In fact, MccH47 and MccE492 present an overall identity of $35 \%$, but the C-terminal regions of the molecule are more homologous. It is noteworthy that microcins E492, 24, H47, V and L share an N-terminal hydrophobic consensus motif GAAGGA (Fig 11). Microcins E492 and H47 are incapable to inhibit the growth of strains carrying mutations in the FepA, Cir and Fiu genes, displaying the necessity of the iron-catecholate receptors for their bioactivity [158-161]. It has been demonstrated that MccE492 uptake by FepA, Fiu and Cir is co-operative, with FepA being the main receptor $[162,163]$. The activity of microcin E492 is dependent on the use of inner membrane complexes that use the proton motive force from the cytoplasmic membrane to transduce ATPs to the outer membrane. It has been shown that the Cterminal serine-rich region, which is highly conserved in the three characterized siderophore-microcins deduced from gene cluster analysis [157], is not required for activity of intracellular microcin [16].

\section{CHALLENGES AND FUTURE}

During the past years, bacteriocins were exposed to extensive modifications on their sequences including substitutions of single, double or multiple amino acids, deletions and insertion of amino acid residues, all in order to get better understanding of their mechanism of actions and develop analogues with better bioactivity. Two main techniques were habitually used for these explorations of SARs. First is the genetic manipulation, or so-called mutagenesis. Second is using synthetic amino acids and solid phase peptide synthetic methods. The mutagenesis or more-specifically, the site-directed 
mutagenesis has been utilized to produce several analogues of bacteriocins that contain a single substitution of amino acid $[48,104]$. The technique is very useful tool in mapping the significant role of single or multiple residues within the peptide sequence. Even though the technique is very useful and incredible in many ways, it has a number of limitations. At the first, it only allows replacements of one or more amino acids with natural amino acids; in other words, it's only limited to natural amino acid-containing peptides $[164,165]$. While it is possible to force bacteria to integrate unnatural amino acids into the sequence [166-168], a better method could be engineering the translational tackle, which can be achieved by generating an aminoacyl-tRNA synthetase and tRNA pair that function self-sufficiently of the synthetases and tRNAs endogenous to the bacteria for instance. Secondly, in order to obtain an analogue of certain peptide, you would need to use the natural producer organism for the production to allow for the prerequisite modification enzymes. The producing mutant peptide could have much higher activity and stronger potency than the parent peptide; this may pass the immunity mechanism of the producing organism causing it to death and stop any further productions of the mutant analogue. Lastly and perhaps the main issue that face mutagenesis is the production of the mutants itself; as the productions relies on the modification, the desired analogue may not be produced at the first place and cannot then be tested.

In contrast to mutagenesis, chemical synthesis has provided peptide analogues with no restriction of amino acids $[165,169]$. The analogues have been produced with unnatural amino acids in both linear and cyclic manner [170]. The chemical route of peptide 
production is often a better technological option than the biotechnological methods for synthesis of medium size peptides that comprise most of the pharmaceutically relevant molecules [165]. However, its limitation comes by increasing the size of the peptide, where insufficient synthesis takes place. Further, certain unusual amino acids are unavailable to be introduced or if they are, it is difficult and challenging to introduce to the sequence and maintain the active form of stereochemistry [171]. Cyclization of certain lasso peptides has also been challenging and almost impossible so far. Another key point in chemical synthesis is that the produced peptides can be easily separated from impurities and side products; racemization during peptide bond formations can be a drawback, however [172].

The use of mutasynthesis, which enables introduction of unnatural amino acids and then subsequent use of enzymes to increase the peptide complexity, seems to offer the advantages of both synthesis and mutagenesis [173, 174]. However, the enzymes stabilities are the main cons of the method. Enzymes are in general labile catalysts, so the engineering process of enzymatic reactions must be intended carefully. This implies that, higher percentage of optimizations of the most relevant operational parameters such as, $\mathrm{pH}$, temperature, used solvents' concentrations and the assessment of both activity and stability are extremely vital. Despite the challenge that face approaches of designing analogues of nature antimicrobial peptides, strategies for synthesis still continue to develop and production of variable analogues are enduring. 
Along all these years, it has been a continuous effort to produce potent analogues of bacteriocins that could have potential use in real applications. Advanced genomics has increased the possibility of designing potent analogues and allowed for better understanding of the SARs of bacteriocins. Owing to reduced cost of genome sequencing, molecular biology approaches with genetic manipulations are considered the favourite route to obtain new bacteriocins analogues. New features of mutants and synthetic analogues were identified and will continue to be probed, which will lead to improvement in the activity spectrum of bacteriocins. New analogues of bacteriocins with improved water solubility [175] and better stability is serum and super activities have been generated [176]. Thus, the future will bring forward new and more efficient antimicrobial bacteriocins based on our knowledge of the biologically produced peptides.

\section{CONCLUSION}

With continuing exploration of bacteriocins and their SARs, our understanding of the structure-function relationships rise and grow incessantly, leading toward the development of new antibacterial molecules with better bactericidal activity, broader target specificity and lower side-effects. Knowledge of the structure activity relationships of bacteriocins provides us with more detailed molecular analysis and vibrant insight of the machinery by which these natural molecules are operating. The SARs among bacteriocins will allow us to develop new antimicrobial peptides tailored for specific applications in food industry and healthcare.

\section{CONFLICT OF INTEREST}


The author(s) confirm that this article content has no conflicts of interest.

\section{ACKNOWLEDGEMENTS}

We acknowledge the Natural Sciences and Engineering Research Council of Canada (NSERC) and Alberta Innovates BioSolutions (AIBS) for generous financial support. Hashem Etayash is the recipient of a Ph.D. scholarship under the Libyan-North American Scholarship Program and the Alberta Innovates Technology Future.

\section{REFERENCES}

[1] Cotter, P. D.; Ross R. P., Hill C. Bacteriocins - a viable alternative to antibiotics? Nat Rev Microbiol, 2013, 11,95-105.

[2] Hassan, M.; Kjos M.; Nes I. F.; Diep D. B., Lotfipour F. Natural antimicrobial peptides from bacteria: characteristics and potential applications to fight against antibiotic resistance. J Appl Microbiol, 2012, 113,723-36.

[3] A, G. Sur unremarquable example d'antagonisme entre deuxsouches de colibacille. $C$ R Seances Soc Biol Fil, 1925, 93.

[4] Perez, R. H.; Zendo T., Sonomoto K. Novel bacteriocins from lactic acid bacteria (LAB): various structures and applications. Microb Cell Fact, 2014, 13 Suppl 1,S3.

[5] Bali, V.; Panesar P. S.; Bera M. B., Kennedy J. F. Bacteriocins: Recent Trends and Potential Applications. Crit Rev Food Sci Nutr, 2014.

[6] Allen, H. K.; Trachsel J.; Looft T., Casey T. A. Finding alternatives to antibiotics. Ann N Y Acad Sci, 2014, 1323,91-100. 
[7] Dischinger, J.; Basi Chipalu S., Bierbaum G. Lantibiotics: promising candidates for future applications in health care. Int J Med Microbiol, 2014, 304,51-62.

[8] Draper, L. A.; Cotter P. D.; Hill C., Ross R. P. Lantibiotic Resistance. Microbiol Mol Biol Rev, 2015, 79,171-91.

[9] Islam, M. R.; Nagao J.; Zendo T., Sonomoto K. Antimicrobial mechanism of lantibiotics. Biochem Soc Trans, 2012, 40,1528-33.

[10] Muller, A.; Ulm H.; Reder-Christ K.; Sahl H. G., Schneider T. Interaction of type A lantibiotics with undecaprenol-bound cell envelope precursors. Microb Drug Resist, 2012, 18,261-70.

[11] Bauer, R., Dicks L. M. Mode of action of lipid II-targeting lantibiotics. Int J Food Microbiol, 2005, 101,201-16.

[12] Kjos, M.; Nes I. F., Diep D. B. Mechanisms of resistance to bacteriocins targeting the mannose phosphotransferase system. Appl Environ Microbiol, 2011, 77,3335-42.

[13] Kjos, M.; Salehian Z.; Nes I. F., Diep D. B. An extracellular loop of the mannose phosphotransferase system component IIC is responsible for specific targeting by class IIa bacteriocins. J Bacteriol, 2010, 192,5906-13.

[14] Kjos, M.; Nes I. F., Diep D. B. Class II one-peptide bacteriocins target a phylogenetically defined subgroup of mannose phosphotransferase systems on sensitive cells. Microbiology, 2009, 155,2949-61.

[15] Bieler, S.; Silva F., Belin D. The polypeptide core of Microcin E492 stably associates with the mannose permease and interferes with mannose metabolism. Res Microbiol, 2010, 161,706-10. 
[16] Bieler, S.; Silva F.; Soto C., Belin D. Bactericidal activity of both secreted and nonsecreted microcin E492 requires the mannose permease. $J$ Bacteriol, 2006, 188,704961.

[17] Gharsallaoui, A.; Oulahal N.; Joly C., Degraeve P. Nisin as a Food Preservative: Part 1: Physicochemical Properties, Antimicrobial Activity, and Main Uses. Crit Rev Food Sci Nutr, 2015,0.

[18] Carolissen-Mackay, V.; Arendse G., Hastings J. W. Purification of bacteriocins of lactic acid bacteria: problems and pointers. Int J Food Microbiol, 1997, 34,1-16.

[19] Rea, M. C.; Alemayehu D.; Casey P. G.; O'Connor P. M.; Lawlor P. G.; Walsh M., et al. Bioavailability of the anti-clostridial bacteriocin thuricin CD in gastrointestinal tract. Microbiology, 2014, 160,439-45.

[20] Rea, M. C.; Alemayehu D.; Ross R. P., Hill C. Gut solutions to a gut problem: bacteriocins, probiotics and bacteriophage for control of Clostridium difficile infection. $J$ Med Microbiol, 2013, 62,1369-78.

[21] Hartmann, H. A.; Wilke T., Erdmann R. Efficacy of bacteriocin-containing cell-free culture supernatants from lactic acid bacteria to control Listeria monocytogenes in food. Int J Food Microbiol, 2011, 146,192-9.

[22] Galvez, A.; Abriouel H.; Lopez R. L., Ben Omar N. Bacteriocin-based strategies for food biopreservation. Int J Food Microbiol, 2007, 120,51-70.

[23] Wilson-Stanford, S.; Kalli A.; Hakansson K.; Kastrantas J.; Orugunty R. S., Smith L. Oxidation of lanthionines renders the lantibiotic nisin inactive. Appl Environ Microbiol, 2009, 75,1381-7. 
[24] Cotter, P. D.; Hill C., Ross R. P. Bacteriocins: developing innate immunity for food. Nat Rev Microbiol, 2005, 3,777-88.

[25] Drider, D., Rebuffat S. Prokaryotic Antimicrobial Peptides: From Genes to Applications: Springer New York; 2011.

[26] Maksimov, M. O.; Pan S. J., James Link A. Lasso peptides: structure, function, biosynthesis, and engineering. Nat Prod Rep, 2012, 29,996-1006.

[27] Duquesne, S.; Destoumieux-Garzon D.; Peduzzi J., Rebuffat S. Microcins, geneencoded antibacterial peptides from enterobacteria. Nat Prod Rep, 2007, 24,708-34.

[28] Arnison, P. G.; Bibb M. J.; Bierbaum G.; Bowers A. A.; Bugni T. S.; Bulaj G., et al. Ribosomally synthesized and post-translationally modified peptide natural products: overview and recommendations for a universal nomenclature. Nat Prod Rep, 2013, $30,108-60$.

[29] Asensio, C., Perez-Diaz J. C. A new family of low molecular weight antibiotics from enterobacteria. Biochem Biophys Res Commun, 1976, 69,7-14.

[30] Cascales, E.; Buchanan S. K.; Duche D.; Kleanthous C.; Lloubes R.; Postle K., et al. Colicin biology. Microbiol Mol Biol Rev, 2007, 71,158-229.

[31] Gillor, O.; Kirkup B. C., Riley M. A. Colicins and microcins: the next generation antimicrobials. Adv Appl Microbiol, 2004, 54,129-46.

[32] Chatterjee, C.; Paul M.; Xie L., van der Donk W. A. Biosynthesis and mode of action of lantibiotics. Chem Rev, 2005, 105,633-84.

[33] Lohans, C. T., Vederas J. C. Structural characterization of thioether-bridged bacteriocins. J Antibiot (Tokyo), 2014, 67,23-30. 
[34] Gotz, F.; Perconti S.; Popella P.; Werner R., Schlag M. Epidermin and gallidermin: Staphylococcal lantibiotics. Int J Med Microbiol, 2014, 304,63-71.

[35] Snyder, A. B., Worobo R. W. Chemical and genetic characterization of bacteriocins: antimicrobial peptides for food safety. J Sci Food Agric, 2014, 94,28-44.

[36] Lee, H., Kim H. Y. Lantibiotics, class I bacteriocins from the genus Bacillus. $J$ Microbiol Biotechnol, 2011, 21,229-35.

[37] Ross, A. C., Vederas J. C. Fundamental functionality: recent developments in understanding the structure-activity relationships of lantibiotic peptides. J Antibiot (Tokyo), 2011, 64,27-34.

[38] Montalban-Lopez, M.; Zhou L.; Buivydas A.; van Heel A. J., Kuipers O. P. Increasing the success rate of lantibiotic drug discovery by Synthetic Biology. Expert Opin Drug Discov, 2012, 7,695-709.

[39] Suda, S.; Cotter P. D.; Hill C., Ross R. P. Lacticin 3147--biosynthesis, molecular analysis, immunity, bioengineering and applications. Curr Protein Pept Sci, 2012, 13,193-204.

[40] Gross, E., Morell J. L. The structure of nisin. J Am Chem Soc, 1971, 93,4634-5.

[41] Szweda, P.; Schielmann M.; Frankowska A.; Kot B., Zalewska M. Antibiotic resistance in Staphylococcus aureus strains isolated from cows with mastitis in eastern Poland and analysis of susceptibility of resistant strains to alternative nonantibiotic agents: lysostaphin, nisin and polymyxin B. J Vet Med Sci, 2014, 76,355-62.

[42] Dosler, S., Mataraci E. In vitro pharmacokinetics of antimicrobial cationic peptides alone and in combination with antibiotics against methicillin resistant Staphylococcus aureus biofilms. Peptides, 2013, 49,53-8. 
[43] Heunis, T. D.; Smith C., Dicks L. M. Evaluation of a nisin-eluting nanofiber scaffold to treat Staphylococcus aureus-induced skin infections in mice. Antimicrob Agents Chemother, 2013, 57,3928-35.

[44] Cotter, P. D.; Hill C., Ross R. P. Bacterial lantibiotics: strategies to improve therapeutic potential. Curr Protein Pept Sci, 2005, 6,61-75.

[45] Rink, R.; Wierenga J.; Kuipers A.; Kluskens L. D.; Driessen A. J.; Kuipers O. P., et al. Dissection and modulation of the four distinct activities of nisin by mutagenesis of rings A and B and by C-terminal truncation. Appl Environ Microbiol, 2007, 73,5809-16. [46] Field, D.; Connor P. M.; Cotter P. D.; Hill C., Ross R. P. The generation of nisin variants with enhanced activity against specific gram-positive pathogens. Mol Microbiol, 2008, 69,218-30.

[47] Field, D.; Begley M.; O'Connor P. M.; Daly K. M.; Hugenholtz F.; Cotter P. D., et al. Bioengineered nisin A derivatives with enhanced activity against both Gram positive and Gram negative pathogens. PLoS One, 2012, 7,e46884.

[48] Healy, B.; Field D.; O'Connor P. M.; Hill C.; Cotter P. D., Ross R. P. Intensive mutagenesis of the nisin hinge leads to the rational design of enhanced derivatives. PLoS One, 2013, 8,e79563.

[49] Zhou, L.; van Heel A. J., Kuipers O. P. The length of a lantibiotic hinge region has profound influence on antimicrobial activity and host specificity. Front Microbiol, 2015, 6,11 .

[50] Molloy, E. M.; Field D.; PM O. C.; Cotter P. D.; Hill C., Ross R. P. Saturation mutagenesis of lysine 12 leads to the identification of derivatives of nisin A with enhanced antimicrobial activity. PLoS One, 2013, 8, e58530. 
[51] Slootweg, J. C.; Peters N.; Quarles van Ufford H. L.; Breukink E.; Liskamp R. M., Rijkers D. T. Semi-synthesis of biologically active nisin hybrids composed of the native lanthionine ABC-fragment and a cross-stapled synthetic DE-fragment. Bioorg Med Chem, 2014, 22,5345-53.

[52] Arnusch, C. J.; Bonvin A. M.; Verel A. M.; Jansen W. T.; Liskamp R. M.; de Kruijff B., et al. The vancomycin-nisin(1-12) hybrid restores activity against vancomycin resistant Enterococci. Biochemistry, 2008, 47,12661-3.

[53] Guiotto, A.; Pozzobon M.; Canevari M.; Manganelli R.; Scarin M., Veronese F. M. PEGylation of the antimicrobial peptide nisin A: problems and perspectives. Farmaco, 2003, 58,45-50.

[54] Balciunas, E. M.; Castillo Martinez F. A.; Todorov S. D.; Franco B. D. G. d. M.; Converti A., Oliveira R. P. d. S. Novel biotechnological applications of bacteriocins: A review. Food Control, 2013, 32,134-42.

[55] Tong, Z.; Ni L., Ling J. Antibacterial peptide nisin: a potential role in the inhibition of oral pathogenic bacteria. Peptides, 2014, 60,32-40.

[56] Eckert, R. Road to clinical efficacy: challenges and novel strategies for antimicrobial peptide development. Future Microbiol, 2011, 6,635-51.

[57] Salomon, R. A., Farias R. N. Microcin 25, a novel antimicrobial peptide produced by Escherichia coli. J Bacteriol, 1992, 174,7428-35.

[58] Blond, A.; Peduzzi J.; Goulard C.; Chiuchiolo M. J.; Barthelemy M.; Prigent Y., et al. The cyclic structure of microcin $\mathrm{J} 25$, a 21-residue peptide antibiotic from Escherichia coli. Eur J Biochem, 1999, 259,747-55. 
[59] Bayro, M. J.; Mukhopadhyay J.; Swapna G. V.; Huang J. Y.; Ma L. C.; Sineva E., et al. Structure of antibacterial peptide microcin J25: a 21-residue lariat protoknot. $J \mathrm{Am}$ Chem Soc, 2003, 125,12382-3.

[60] Wilson, K. A.; Kalkum M.; Ottesen J.; Yuzenkova J.; Chait B. T.; Landick R., et al. Structure of microcin J25, a peptide inhibitor of bacterial RNA polymerase, is a lassoed tail. J Am Chem Soc, 2003, 125,12475-83.

[61] Rosengren, K. J.; Clark R. J.; Daly N. L.; Goransson U.; Jones A., Craik D. J. Microcin J25 has a threaded sidechain-to-backbone ring structure and not a head-to-tail cyclized backbone. J Am Chem Soc, 2003, 125,12464-74.

[62] Blond, A.; Cheminant M.; Destoumieux-Garzon D.; Segalas-Milazzo I.; Peduzzi J.; Goulard C., et al. Thermolysin-linearized microcin J25 retains the structured core of the native macrocyclic peptide and displays antimicrobial activity. Eur $J$ Biochem, 2002, $269,6212-22$.

[63] Rosengren, K. J.; Blond A.; Afonso C.; Tabet J.-C.; Rebuffat S., Craik D. J. Structure of Thermolysin Cleaved Microcin J25: Extreme Stability of a Two-Chain Antimicrobial Peptide Devoid of Covalent Links $\dagger$, + Biochemistry, 2004, 43,4696-702.

[64] Rebuffat, S.; Blond A.; Destoumieux-Garzon D.; Goulard C., Peduzzi J. Microcin J25, from the macrocyclic to the lasso structure: implications for biosynthetic, evolutionary and biotechnological perspectives. Curr Protein Pept Sci, 2004, 5,383-91.

[65] Bellomio, A.; Vincent P. A.; de Arcuri B. F.; Salomon R. A.; Morero R. D., Farias R. N. The microcin $\mathrm{J} 25$ beta-hairpin region is important for antibiotic uptake but not for RNA polymerase and respiration inhibition. Biochem Biophys Res Commun, 2004, $325,1454-8$. 
[66] Semenova, E.; Yuzenkova Y.; Peduzzi J.; Rebuffat S., Severinov K. Structureactivity analysis of microcinJ25: distinct parts of the threaded lasso molecule are responsible for interaction with bacterial RNA polymerase. J Bacteriol, 2005, 187,385963.

[67] Pavlova, O.; Mukhopadhyay J.; Sineva E.; Ebright R. H., Severinov K. Systematic structure-activity analysis of microcin J25. J Biol Chem, 2008, 283,25589-95.

[68] Pan, S. J., Link A. J. Sequence diversity in the lasso peptide framework: discovery of functional microcin $\mathrm{J} 25$ variants with multiple amino acid substitutions. $J$ Am Chem Soc, 2011, 133,5016-23.

[69] Soudy, R.; Wang L., Kaur K. Synthetic peptides derived from the sequence of a lasso peptide microcin J25 show antibacterial activity. Bioorg Med Chem, 2012, 20,1794800.

[70] Ducasse, R.; Yan K. P.; Goulard C.; Blond A.; Li Y.; Lescop E., et al. Sequence determinants governing the topology and biological activity of a lasso peptide, microcin J25. Chembiochem, 2012, 13,371-80.

[71] Piscotta, F. J.; Tharp J. M.; Liu W. R., Link A. J. Expanding the chemical diversity of lasso peptide MccJ25 with genetically encoded noncanonical amino acids. Chem Commun (Camb), 2015, 51,409-12.

[72] Mathavan, I.; Zirah S.; Mehmood S.; Choudhury H. G.; Goulard C.; Li Y., et al. Structural basis for hijacking siderophore receptors by antimicrobial lasso peptides. Nat Chem Biol, 2014, 10,340-2.

[73] Parks, W. M.; Bottrill A. R.; Pierrat O. A.; Durrant M. C., Maxwell A. The action of the bacterial toxin, microcin B17, on DNA gyrase. Biochimie, 2007, 89,500-7. 
[74] Davagnino, J.; Herrero M.; Furlong D.; Moreno F., Kolter R. The DNA replication inhibitor microcin B17 is a forty-three-amino-acid protein containing sixty percent glycine. Proteins, 1986, 1,230-8.

[75] Herrero, M., Moreno F. Microcin B17 blocks DNA replication and induces the SOS system in Escherichia coli. J Gen Microbiol, 1986, 132,393-402.

[76] Vizan, J. L.; Hernandez-Chico C.; del Castillo I., Moreno F. The peptide antibiotic microcin B17 induces double-strand cleavage of DNA mediated by E. coli DNA gyrase. EMBO J, 1991, 10,467-76.

[77] Pierrat, O. A., Maxwell A. Evidence for the role of DNA strand passage in the mechanism of action of microcin B17 on DNA gyrase. Biochemistry, 2005, 44,4204-15.

[78] Yorgey, P.; Lee J.; Kordel J.; Vivas E.; Warner P.; Jebaratnam D., et al. Posttranslational modifications in microcin B17 define an additional class of DNA gyrase inhibitor. Proc Natl Acad Sci U S A, 1994, 91,4519-23.

[79] Yorgey, P.; Davagnino J., Kolter R. The maturation pathway of microcin B17, a peptide inhibitor of DNA gyrase. Mol Microbiol, 1993, 9,897-905.

[80] Zamble, D. B.; Miller D. A.; Heddle J. G.; Maxwell A.; Walsh C. T., Hollfelder F. In vitro characterization of DNA gyrase inhibition by microcin B17 analogs with altered bisheterocyclic sites. Proc Natl Acad Sci U S A, 2001, 98,7712-7.

[81] Sinha Roy, R.; Kelleher N. L.; Milne J. C., Walsh C. T. In vivo processing and antibiotic activity of microcin B17 analogs with varying ring content and altered bisheterocyclic sites. Chem Biol, 1999, 6,305-18. 
[82] Asensio, C.; Pérez-Díaz J. C.; Martínez M. C., Baquero F. A new family of low molecular weight antibiotics from enterobacteria. Biochem Biophys Res Commun, 1976, 69,7-14.

[83] San Millan, J. L.; Hernandez-Chico C.; Pereda P., Moreno F. Cloning and mapping of the genetic determinants for microcin B17 production and immunity. $J$ Bacteriol, $1985,163,275-81$.

[84] Collin, F.; Karkare S., Maxwell A. Exploiting bacterial DNA gyrase as a drug target: current state and perspectives. Appl Microbiol Biotechnol, 2011, 92,479-97.

[85] Sinha Roy, R.; Belshaw P. J., Walsh C. T. Mutational analysis of posttranslational heterocycle biosynthesis in the gyrase inhibitor microcin B17: distance dependence from propeptide and tolerance for substitution in a GSCG cyclizable sequence. Biochemistry, $1998,37,4125-36$.

[86] Parks, W. M.; Bottrill A. R.; Pierrat O. A.; Durrant M. C., Maxwell A. The action of the bacterial toxin, microcin B17, on DNA gyrase. Biochimie, 2007, 89,500-7.

[87] Thompson, R. E.; Collin F.; Maxwell A.; Jolliffe K. A., Payne R. J. Synthesis of full length and truncated microcin B17 analogues as DNA gyrase poisons. Org Biomol Chem, 2014, $12,1570-8$.

[88] Shkundina, I.; Serebryakova M., Severinov K. The C-terminal part of microcin B is crucial for DNA gyrase inhibition and antibiotic uptake by sensitive cells. $J$ Bacteriol, 2014, 196,1759-67.

[89] Severinov, K., Nair S. K. Microcin C: biosynthesis and mechanisms of bacterial resistance. Future Microbiol, 2012, 7,281-9. 
[90] Severinov, K.; Semenova E.; Kazakov A.; Kazakov T., Gelfand M. S. Lowmolecular-weight post-translationally modified microcins. Mol Microbiol, 2007, $65,1380-94$.

[91] Novikova, M.; Metlitskaya A.; Datsenko K.; Kazakov T.; Kazakov A.; Wanner B., et al. The Escherichia coli Yej transporter is required for the uptake of translation inhibitor microcin C. J Bacteriol, 2007, 189,8361-5.

[92] Vondenhoff, G. H.; Blanchaert B.; Geboers S.; Kazakov T.; Datsenko K. A.; Wanner B. L., et al. Characterization of peptide chain length and constituency requirements for YejABEF-mediated uptake of microcin C analogues. J Bacteriol, 2011, 193,3618-23.

[93] Kazakov, T.; Vondenhoff G. H.; Datsenko K. A.; Novikova M.; Metlitskaya A.; Wanner B. L., et al. Escherichia coli peptidase $\mathrm{A}, \mathrm{B}$, or $\mathrm{N}$ can process translation inhibitor microcin C. J Bacteriol, 2008, 190,2607-10.

[94] Kazakov, T.; Metlitskaya A., Severinov K. Amino acid residues required for maturation, cell uptake, and processing of translation inhibitor microcin C. J Bacteriol, 2007, 189,2114-8.

[95] Van de Vijver, P.; Vondenhoff G. H.; Kazakov T. S.; Semenova E.; Kuznedelov K.; Metlitskaya A., et al. Synthetic microcin C analogs targeting different aminoacyl-tRNA synthetases. J Bacteriol, 2009, 191,6273-80.

[96] Vondenhoff, G. H.; Dubiley S.; Severinov K.; Lescrinier E.; Rozenski J., Van Aerschot A. Extended targeting potential and improved synthesis of Microcin C analogs as antibacterials. Bioorg Med Chem, 2011, 19,5462-7. 
[97] Nissen-Meyer, J.; Rogne P.; Oppegard C.; Haugen H. S., Kristiansen P. E. Structurefunction relationships of the non-lanthionine-containing peptide (class II) bacteriocins produced by gram-positive bacteria. Curr Pharm Biotechnol, 2009, 10,19-37.

[98] Drider, D.; Fimland G.; Hechard Y.; McMullen L. M., Prevost H. The continuing story of class IIa bacteriocins. Microbiol Mol Biol Rev, 2006, 70,564-82.

[99] Fimland, G.; Johnsen L.; Dalhus B., Nissen-Meyer J. Pediocin-like antimicrobial peptides (class IIa bacteriocins) and their immunity proteins: biosynthesis, structure, and mode of action. $J$ Pept Sci, 2005, 11,688-96.

[100] Oppegard, C.; Rogne P.; Emanuelsen L.; Kristiansen P. E.; Fimland G., NissenMeyer J. The two-peptide class II bacteriocins: structure, production, and mode of action. J Mol Microbiol Biotechnol, 2007, 13,210-9.

[101] Nissen-Meyer, J.; Oppegard C.; Rogne P.; Haugen H. S., Kristiansen P. E. Structure and Mode-of-Action of the Two-Peptide (Class-IIb) Bacteriocins. Probiotics Antimicrob Proteins, 2010, 2,52-60.

[102] Papagianni, M., Anastasiadou S. Pediocins: The bacteriocins of Pediococci. Sources, production, properties and applications. Microb Cell Fact, 2009, 8,3.

[103] Tominaga, T., Hatakeyama Y. Development of innovative pediocin PA-1 by DNA shuffling among class IIa bacteriocins. Appl Environ Microbiol, 2007, 73,5292-9.

[104] Song, D. F.; Li X.; Zhang Y. H.; Zhu M. Y., Gu Q. Mutational analysis of positively charged residues in the $\mathrm{N}$-terminal region of the class IIa bacteriocin pediocin PA-1. Lett Appl Microbiol, 2014, 58,356-61. 
[105] Kazazic, M.; Nissen-Meyer J., Fimland G. Mutational analysis of the role of charged residues in target-cell binding, potency and specificity of the pediocin-like bacteriocin sakacin P. Microbiology, 2002, 148,2019-27.

[106] Haugen, H. S.; Fimland G., Nissen-Meyer J. Mutational analysis of residues in the helical region of the class IIa bacteriocin pediocin PA-1. Appl Environ Microbiol, 2011, 77,1966-72.

[107] Fimland, G.; Jack R.; Jung G.; Nes I. F., Nissen-Meyer J. The bactericidal activity of pediocin PA-1 is specifically inhibited by a 15 -mer fragment that spans the bacteriocin from the center toward the C terminus. Appl Environ Microbiol, 1998, 64,5057-60.

[108] Tiwari, S. K.; Sutyak Noll K.; Cavera V. L., Chikindas M. L. Improved Antimicrobial Activities of Synthetic-Hybrid Bacteriocins Designed from Enterocin E5052 and Pediocin PA-1. Appl Environ Microbiol, 2015, 81,1661-7.

[109] Rodriguez, J. M.; Martinez M. I., Kok J. Pediocin PA-1, a wide-spectrum bacteriocin from lactic acid bacteria. Crit Rev Food Sci Nutr, 2002, 42,91-121.

[110] Fimland, G.; Johnsen L.; Dalhus B., Nissen-Meyer J. Pediocin-like antimicrobial peptides (class IIa bacteriocins) and their immunity proteins: biosynthesis, structure, and mode of action. Journal of Peptide Science, 2005, 11,688-96.

[111] Cui, Y. H.; Zhang C.; Wang Y. F.; Shi J.; Zhang L. W.; Ding Z. Q., et al. Class IIa Bacteriocins: Diversity and New Developments. International Journal of Molecular Sciences, 2012, 13,16668-703.

[112] Bodapati, K. C.; Soudy R.; Etayash H.; Stiles M., Kaur K. Design, synthesis and evaluation of antimicrobial activity of N-terminal modified Leucocin A analogues. Bioorg Med Chem, 2013, 21,3715-22. 
[113] Hastings, J. W.; Sailer M.; Johnson K.; Roy K. L.; Vederas J. C., Stiles M. E. Characterization of leucocin A-UAL 187 and cloning of the bacteriocin gene from Leuconostoc gelidum. J Bacteriol, 1991, 173,7491-500.

[114] Fregeau Gallagher, N. L.; Sailer M.; Niemczura W. P.; Nakashima T. T.; Stiles M. E., Vederas J. C. Three-dimensional structure of leucocin A in trifluoroethanol and dodecylphosphocholine micelles: spatial location of residues critical for biological activity in type IIa bacteriocins from lactic acid bacteria. Biochemistry, 1997, 36,1506272.

[115] Yan, L. Z.; Gibbs A. C.; Stiles M. E.; Wishart D. S., Vederas J. C. Analogues of bacteriocins: antimicrobial specificity and interactions of leucocin A with its enantiomer, carnobacteriocin B2, and truncated derivatives. J Med Chem, 2000, 43,4579-81.

[116] Dalet, K.; Cenatiempo Y.; Cossart P., Hechard Y. A sigma(54)-dependent PTS permease of the mannose family is responsible for sensitivity of Listeria monocytogenes to mesentericin Y105. Microbiology, 2001, 147,3263-9.

[117] Arous, S.; Dalet K., Hechard Y. Involvement of the mpo operon in resistance to class IIa bacteriocins in Listeria monocytogenes. FEMS Microbiol Lett, 2004, 238,37-41. [118] Vu-Khac, H., Miller K. W. Regulation of mannose phosphotransferase system permease and virulence gene expression in Listeria monocytogenes by the EII(t)Man transporter. Appl Environ Microbiol, 2009, 75,6671-8.

[119] Derksen, D. J.; Stymiest J. L., Vederas J. C. Antimicrobial leucocin analogues with a disulfide bridge replaced by a carbocycle or by noncovalent interactions of allyl glycine residues. J Am Chem Soc, 2006, 128,14252-3. 
[120] Derksen, D. J.; Boudreau M. A., Vederas J. C. Hydrophobic interactions as substitutes for a conserved disulfide linkage in the type IIa bacteriocins, leucocin A and pediocin PA-1. Chembiochem, 2008, 9,1898-901.

[121] Etayash, H.; Norman L.; Thundat T., Kaur K. Peptide-bacteria interactions using engineered surface-immobilized peptides from class IIa bacteriocins. Langmuir, 2013, $29,4048-56$.

[122] Etayash, H.; Norman L.; Thundat T.; Stiles M., Kaur K. Surface-conjugated antimicrobial peptide leucocin a displays high binding to pathogenic gram-positive bacteria. ACS Appl Mater Interfaces, 2014, 6,1131-8.

[123] Etayash, H.; Jiang K.; Thundat T., Kaur K. Impedimetric detection of pathogenic Gram-positive bacteria using an antimicrobial peptide from class IIa bacteriocins. Anal Chem, 2014, 86,1693-700.

[124] Azmi, S.; Jiang K.; Stiles M.; Thundat T., Kaur K. Detection of Listeria monocytogenes with Short Peptide Fragments from Class IIa Bacteriocins as Recognition Elements. ACS Comb Sci, 2015, 17,156-63.

[125] Tichaczek, P. S.; Vogel R. F., Hammes W. P. Cloning and sequencing of sakP encoding sakacin P, the bacteriocin produced by Lactobacillus sake LTH 673 . Microbiology, 1994, 140 ( Pt 2),361-7.

[126] Fimland, G.; Johnsen L.; Axelsson L.; Brurberg M. B.; Nes I. F.; Eijsink V. G., et al. A C-terminal disulfide bridge in pediocin-like bacteriocins renders bacteriocin activity less temperature dependent and is a major determinant of the antimicrobial spectrum. $J$ Bacteriol, 2000, 182,2643-8. 
[127] Kazazic, M.; Nissen-Meyer J., Fimland G. Mutational analysis of the role of charged residues in target-cell binding, potency and specificity of the pediocin-like bacteriocin sakacin P. Microbiology, 2002, 148,2019-27.

[128] Fimland, G.; Pirneskoski J.; Kaewsrichan J.; Jutila A.; Kristiansen P. E.; Kinnunen P. K., et al. Mutational analysis and membrane-interactions of the beta-sheet-like Nterminal domain of the pediocin-like antimicrobial peptide sakacin P. Biochim Biophys Acta, 2006, 1764,1132-40.

[129] Nissen-Meyer, J., Nes I. F. Ribosomally synthesized antimicrobial peptides: their function, structure, biogenesis, and mechanism of action. Arch Microbiol, 1997, 167,6777.

[130] Papagianni, M. Ribosomally synthesized peptides with antimicrobial properties: biosynthesis, structure, function, and applications. Biotechnol Adv, 2003, 21,465-99.

[131] Nissen-Meyer, J.; Holo H.; Havarstein L. S.; Sletten K., Nes I. F. A novel lactococcal bacteriocin whose activity depends on the complementary action of two peptides. J Bacteriol, 1992, 174,5686-92.

[132] Ghrairi, T.; Frere J.; Berjeaud J. M., Manai M. Lactococcin MMT24, a novel twopeptide bacteriocin produced by Lactococcus lactis isolated from rigouta cheese. Int $J$ Food Microbiol, 2005, 105,389-98.

[133] Moll, G.; Ubbink-Kok T.; Hildeng-Hauge H.; Nissen-Meyer J.; Nes I. F.; Konings W. N., et al. Lactococcin $\mathrm{G}$ is a potassium ion-conducting, two-component bacteriocin. $J$ Bacteriol, 1996, 178,600-5.

[134] Anderssen, E. L.; Diep D. B.; Nes I. F.; Eijsink V. G., Nissen-Meyer J. Antagonistic activity of Lactobacillus plantarum C11: two new two-peptide bacteriocins, 
plantaricins EF and JK, and the induction factor plantaricin A. Appl Environ Microbiol, 1998, 64,2269-72.

[135] Oppegard, C.; Fimland G.; Thorbaek L., Nissen-Meyer J. Analysis of the twopeptide bacteriocins lactococcin $\mathrm{G}$ and enterocin 1071 by site-directed mutagenesis. $\mathrm{Appl}$ Environ Microbiol, 2007, 73,2931-8.

[136] Zendo, T.; Koga S.; Shigeri Y.; Nakayama J., Sonomoto K. Lactococcin Q, a novel two-peptide bacteriocin produced by Lactococcus lactis QU 4. Appl Environ Microbiol, 2006, 72,3383-9.

[137] Fimland, N.; Rogne P.; Fimland G.; Nissen-Meyer J., Kristiansen P. E. Threedimensional structure of the two peptides that constitute the two-peptide bacteriocin plantaricin EF. Biochim Biophys Acta, 2008, 1784,1711-9.

[138] Hauge, H. H.; Mantzilas D.; Eijsink V. G., Nissen-Meyer J. Membrane-mimicking entities induce structuring of the two-peptide bacteriocins plantaricin $\mathrm{E} / \mathrm{F}$ and plantaricin J/K. J Bacteriol, 1999, 181,740-7.

[139] Rogne, P.; Fimland G.; Nissen-Meyer J., Kristiansen P. E. Three-dimensional structure of the two peptides that constitute the two-peptide bacteriocin lactococcin G. Biochim Biophys Acta, 2008, 1784,543-54.

[140] Rogne, P.; Haugen C.; Fimland G.; Nissen-Meyer J., Kristiansen P. E. Threedimensional structure of the two-peptide bacteriocin plantaricin JK. Peptides, 2009, $30,1613-21$.

[141] Senes, A.; Engel D. E., DeGrado W. F. Folding of helical membrane proteins: the role of polar, GxxxG-like and proline motifs. Curr Opin Struct Biol, 2004, 14,465-79. 
[142] Senes, A.; Gerstein M., Engelman D. M. Statistical analysis of amino acid patterns in transmembrane helices: the GxxxG motif occurs frequently and in association with beta-branched residues at neighboring positions. J Mol Biol, 2000, 296,921-36.

[143] Senes, A.; Ubarretxena-Belandia I., Engelman D. M. The Calpha ---H...O hydrogen bond: a determinant of stability and specificity in transmembrane helix interactions. Proc Natl Acad Sci U S A, 2001, 98,9056-61.

[144] Oppegard, C.; Schmidt J.; Kristiansen P. E., Nissen-Meyer J. Mutational analysis of putative helix-helix interacting GxxxG-motifs and tryptophan residues in the twopeptide bacteriocin lactococcin G. Biochemistry, 2008, 47,5242-9.

[145] Soliman, W.; Wang L.; Bhattacharjee S., Kaur K. Structure-activity relationships of an antimicrobial peptide plantaricin s from two-peptide class IIb bacteriocins. $J$ Med Chem, 2011, 54,2399-408.

[146] Cotter, P.; Ross R., Hill C. Bacteriocins - a viable alternative to antibiotics? Nat Rev Microbiol, 2013, 11,95 - 105.

[147] Rebuffat, S. Microcins in action: amazing defence strategies of Enterobacteria. Biochem Soc Trans, 2012, 40,1456-62.

[148] Arnison, P. G.; Bibb M. J.; Bierbaum G.; Bowers A. A.; Bugni T. S.; Bulaj G., et al. Ribosomally synthesized and post-translationally modified peptide natural products: overview and recommendations for a universal nomenclature. Nat Prod Rep, 2013, 30,108-60.

[149] Pons, A. M.; Delalande F.; Duarte M.; Benoit S.; Lanneluc I.; Sable S., et al. Genetic analysis and complete primary structure of microcin L. Antimicrob Agents Chemother, 2004, 48,505-13. 
[150] O'Brien, G. J., Mahanty H. K. Colicin 24, a new plasmid-borne colicin from a uropathogenic strain of Escherichia coli. Plasmid, 1994, 31,288-96.

[151] Morin, N.; Lanneluc I.; Connil N.; Cottenceau M.; Pons A. M., Sable S. Mechanism of bactericidal activity of microcin L in Escherichia coli and Salmonella enterica. Antimicrob Agents Chemother, 2011, 55,997-1007.

[152] Stiles, M. E.; Wang L., van Belkum M. J. Expression vectors for treating bacterial infections 2008.

[153] Wooley, R. E.; Gibbs P. S., Shotts E. B., Jr. Inhibition of Salmonella typhimurium in the chicken intestinal tract by a transformed avirulent avian Escherichia coli. Avian Dis, 1999, 43,245-50.

[154] Corsini, G.; Karahanian E.; Tello M.; Fernandez K.; Rivero D.; Saavedra J. M., et al. Purification and characterization of the antimicrobial peptide microcin N. FEMS Microbiol Lett, 2010, 312,119-25.

[155] de Lorenzo, V. Isolation and characterization of microcin E492 from Klebsiella pneumoniae. Arch Microbiol, 1984, 139,72-5.

[156] de Lorenzo, V., Pugsley A. P. Microcin E492, a low-molecular-weight peptide antibiotic which causes depolarization of the Escherichia coli cytoplasmic membrane. Antimicrob Agents Chemother, 1985, 27,666-9.

[157] Vassiliadis, G.; Destoumieux-Garzon D.; Lombard C.; Rebuffat S., Peduzzi J. Isolation and characterization of two members of the siderophore-microcin family, microcins M and H47. Antimicrob Agents Chemother, 2010, 54,288-97. 
[158] Thomas, X.; Destoumieux-Garzon D.; Peduzzi J.; Afonso C.; Blond A.; Birlirakis N., et al. Siderophore peptide, a new type of post-translationally modified antibacterial peptide with potent activity. $J$ Biol Chem, 2004, 279,28233-42.

[159] Vassiliadis, G.; Peduzzi J.; Zirah S.; Thomas X.; Rebuffat S., Destoumieux-Garzon D. Insight into siderophore-carrying peptide biosynthesis: enterobactin is a precursor for microcin E492 posttranslational modification. Antimicrob Agents Chemother, 2007, $51,3546-53$.

[160] Nolan, E. M.; Fischbach M. A.; Koglin A., Walsh C. T. Biosynthetic tailoring of microcin E492m: post-translational modification affords an antibacterial siderophorepeptide conjugate. J Am Chem Soc, 2007, 129,14336-47.

[161] Nolan, E. M., Walsh C. T. Investigations of the MceIJ-catalyzed posttranslational modification of the microcin E492 C-terminus: linkage of ribosomal and nonribosomal peptides to form "trojan horse" antibiotics. Biochemistry, 2008, 47,9289-99.

[162] Strahsburger, E.; Baeza M.; Monasterio O., Lagos R. Cooperative uptake of microcin E492 by receptors FepA, Fiu, and Cir and inhibition by the siderophore enterochelin and its dimeric and trimeric hydrolysis products. Antimicrob Agents Chemother, 2005, 49,3083-6.

[163] Lagos, R.; Tello M.; Mercado G.; Garcia V., Monasterio O. Antibacterial and antitumorigenic properties of microcin E492, a pore-forming bacteriocin. Curr Pharm Biotechnol, 2009, 10,74-85.

[164] Chalker, J. M., Davis B. G. Chemical mutagenesis: selective post-expression interconversion of protein amino acid residues. Curr Opin Chem Biol, 2010, 14,781-9. 
[165] Nilsson, B. L.; Soellner M. B., Raines R. T. Chemical Synthesis of Proteins. Annual review of biophysics and biomolecular structure, 2005, 34,91-118.

[166] Chalker, J. M.; Bernardes G. J., Davis B. G. A "tag-and-modify" approach to siteselective protein modification. Acc Chem Res, 2011, 44,730-41.

[167] de Graaf, A. J.; Kooijman M.; Hennink W. E., Mastrobattista E. Nonnatural amino acids for site-specific protein conjugation. Bioconjug Chem, 2009, 20,1281-95.

[168] Shozen, N.; Iijima I., Hohsaka T. Site-specific incorporation of PEGylated amino acids into proteins using nonnatural amino acid mutagenesis. Bioorg Med Chem Lett, 2009, 19,4909-11.

[169] Jakopin, Z. The design and synthesis of Ala-Glu/iGln mimetics: heterocyclic building blocks for pseudopeptides. Tetrahedron Letters, 2015, 56,504-6.

[170] Zheng, J. S.; Tang S.; Huang Y. C., Liu L. Development of new thioester equivalents for protein chemical synthesis. Acc Chem Res, 2013, 46,2475-84.

[171] Knerr, P. J., van der Donk W. A. Chemical synthesis of the lantibiotic lacticin 481 reveals the importance of lanthionine stereochemistry. J Am Chem Soc, 2013, 135,70947.

[172] Stolze, S. C., Kaiser M. Challenges in the Syntheses of Peptidic Natural Products. Synthesis-Stuttgart, 2012, 44,1755-77.

[173] Guzman, F.; Barberis S., Illanes A. Peptide synthesis: chemical or enzymatic. Electronic Journal of Biotechnology, 2007, 10,279-314.

[174] Sundermann, U.; Bravo-Rodriguez K.; Klopries S.; Kushnir S.; Gomez H.; Sanchez-Garcia E., et al. Enzyme-directed mutasynthesis: a combined experimental and 
theoretical approach to substrate recognition of a polyketide synthase. ACS Chem Biol, 2013, 8,443-50.

[175] Rollema, H. S.; Kuipers O. P.; Both P.; de Vos W. M., Siezen R. J. Improvement of solubility and stability of the antimicrobial peptide nisin by protein engineering. Appl Environ Microbiol, 1995, 61,2873-8.

[176] Liu, W., Hansen J. N. Enhancement of the chemical and antimicrobial properties of subtilin by site-directed mutagenesis. $J$ Biol Chem, 1992, 267,25078-85. 